\title{
Evaluation of 2-acetyl-1-pyrroline in foods, with an emphasis on rice flavour
}

Article

Accepted Version

Creative Commons: Attribution-Noncommercial-No Derivative Works 4.0

Wei, X., Handoko, D. D., Pather, L., Methven, L. and Elmore, J. S. (2017) Evaluation of 2-acetyl-1-pyrroline in foods, with an emphasis on rice flavour. Food Chemistry, 232. pp. 531-544. ISSN 0308-8146 doi:

https://doi.org/10.1016/j.foodchem.2017.04.005 Available at https://centaur.reading.ac.uk/69971/

It is advisable to refer to the publisher's version if you intend to cite from the work. See Guidance on citing.

To link to this article DOI: http://dx.doi.org/10.1016/j.foodchem.2017.04.005

Publisher: Elsevier

All outputs in CentAUR are protected by Intellectual Property Rights law, including copyright law. Copyright and IPR is retained by the creators or other copyright holders. Terms and conditions for use of this material are defined in the End User Agreement.

\section{www.reading.ac.uk/centaur}

\section{CentAUR}

Central Archive at the University of Reading 
Reading's research outputs online 
1 Evaluation of 2-acetyl-1-pyrroline in foods, with an emphasis on rice

2 flavour

3 Xuan Wei ${ }^{\mathrm{a}}$, Dody D. Handoko ${ }^{\mathrm{b}}$, Leela Pather ${ }^{\mathrm{a}}$, Lisa Methven ${ }^{\mathrm{a}}$, J. Stephen Elmore ${ }^{\mathrm{a} *}$

$4 \quad{ }^{a}$ Department of Food and Nutritional Sciences, University of Reading, Whiteknights,

$5 \quad$ Reading RG6 6AP, UK

$6 \quad{ }^{\mathrm{b}}$ Indonesian Centre for Rice Research, Cikampek, Subang 41256, West Java, Indonesia

7

$8 \quad *$ Corresponding author. Tel.: +44 118 3787455; fax: +44 1183787708.

$9 \quad$ E-mail address: j.s.elmore@reading.ac.uk (J.S. Elmore).

10 
12 The popcorn-like aroma compound 2-acetyl-1-pyrroline (2-AP) is a key contributor to the desirable aroma of fragrant rice and is also important in the aroma of other foods, such as

14 pandan leaf, popcorn and Mediterranean sausage. It can be formed enzymatically in the rice

15 grain as it grows and is also formed, as part of the Maillard reaction, when rice is heated. This

16 review examines the formation of 2-AP in rice and other foods, particularly its formation

17 during cooking, focusing on the importance of the Maillard reaction between reducing sugar breakdown products and 1-pyrroline derived from the amino acids proline and ornithine. The synthesis of 2-AP is discussed alongside the attempts that have been made to stabilise this relatively unstable compound. The analysis of 2-AP by instrumental techniques, particularly gas chromatography-mass spectrometry and gas chromatography-olfactometry, alongside the use of sensory studies, is also discussed.

Keywords: 2-acetyl-1-pyrroline, 2-AP, flavour, rice, pandan, popcorn, Maillard reaction, biosynthesis, analysis 


\section{Introduction}

The IUPAC name of 2-acetyl-1-pyrroline (2-AP) is 1-(3,4-dihydro-2H-pyrrol-5yl)ethanone, its CAS number is 85213-22-5 and its FEMA (Flavor and Extract Manufacturers Association) number is 4249. 2-AP was first identified in rice by Buttery, Ling, and Juliano (1982), and is regarded as the most important aroma compound in rice, especially fragrant rice (Buttery, Ling, Juliano, \& Turnbaugh, 1983). In that study, $0.05 \mathrm{ppm}$ 2-AP was described as popcorn-like and its odour threshold in water was measured as $0.1 \mathrm{~nL} / \mathrm{L}$, while its odour threshold in air was reported by Schieberle (1991) as $0.02 \mathrm{ng} / \mathrm{L}$; this very low threshold makes it an important contributor to a food's aroma when present. As well as rice, it is also a key flavour compound in many cereal products, as well as some vegetable and animal products (Adams \& De Kimpe, 2006; Wakte, Zanan, Hinge, Khandagale, Nadaf, \& Henry, 2016).

Bioformation of 2-acetyl-1-pyrroline in both plants and microorganisms has been studied and several types of bacteria are able to form this compound (see Part 3 of this review). 2-Acetyl-1-pyrroline has also been shown to form in the Maillard reaction; it can be formed from the reaction between proline and reducing sugars/sugar degradation products upon heating (Schieberle, 1989).

Although there is a high commercial interest in 2-AP because of its desirable sensory attributes, the instability of this compound is a significant problem for its commercial application. Pure 2-AP will turn red and degrade within 10 minutes at 
room temperature (Fang \& Cadwallader, 2014), and there is significant short-term reduction of 2-AP concentration in food products, such as popcorn (Schieberle, 1995) and raw fragrant rice (Widjaja, Craske, \& Wootton, 1996a).

The occurrence of 2-acetyl-1-pyrroline in food products, its bioformation and thermal formation, synthesis, stabilisation, analysis and sensory evaluation will be reviewed in this paper, with particular emphasis on the role of 2-AP in fragrant rice aroma.

\section{Food sources of 2-acetyl-1-pyrroline}

\subsection{Rice}

Non-fragrant rice (long and medium grain indicas and short grain japonicas), mainly grown in USA, Vietnam, Thailand and Australia, constitutes around $80 \%$ of the world rice trade (Singh, Singh, \& Khush, 2000). Major producers of fragrant rice are India, Pakistan and Thailand. Most of the fragrant rice exported from India and Pakistan is basmati, while fragrant jasmine rice is a major export of Thailand (Singh et al., 2000). In 2010, Thailand was the biggest exporter of fragrant rice: 2.65 million tonnes of jasmine rice were exported, followed by India (1.80 million tonnes basmati) and Pakistan (1.05 million tonnes basmati) (Slayton \& Muniroth, 2011).

The price of fragrant rice is much higher than that of non-fragrant rice. For example, high-quality fragrant basmati rice has a three times higher price than high quality non-fragrant rice. The commercial value of fragrant rice is higher than that of 
non-fragrant rice, partly because fragrant rice varieties are relatively low yielding. Fragrant rice is less resistant to disease and insect pests and is prone to high shedding, leading to losses in yield (Berner \& Hoff, 1986; Golam et al., 2011). It has been shown that higher quality grains with stronger aromas are generated in crops grown in drought and saline conditions (Yoshihashi, Nguyen, \& Kabaki, 2004). These adverse conditions do not favour high yields.

2-AP is the key discriminator between fragrant and non-fragrant rice and many studies have focused on the concentration of 2-AP in different rice cultivars. 2-AP concentrations in different fragrant cultivars vary substantially (Table 1). For example, 2-AP was present in milled Fowler Gourmet Aromatic rice (a US-grown aromatic rice) at $999 \mu \mathrm{g} / \mathrm{kg}$, while, in a set of five basmati samples, levels of 2-AP from 19 $\mu \mathrm{g} / \mathrm{kg}$ to $342 \mu \mathrm{g} / \mathrm{kg}$ were measured (Bergman, Delgado, Bryant, Grimm, Cadwallader, $\&$ Webb, 2000).

Milled rice (commonly referred to as white rice) is obtained from the milling of brown rice to remove the outer bran layer. Whole rice grains are dehulled; then the dehulled (brown) rice is milled twice. Generally, $20-22 \%$ of the rice grain is hull, and another $8-10 \%$ is bran and embryo; therefore, the yield of milled rice is around $70 \%$ (Singh et al., 2000). As can be seen in Table 1, in most cases more 2-AP is present in brown rice compared to milled rice.

Caution should be applied when comparing data acquired by different authors. In some cases 2-AP was measured in uncooked rice (e.g., Hopfer, Jodari, NegreZakharov, Wylie, \& Ebeler, 2016), while in other cases the rice was cooked before 
analysis (e.g., Widjaja et al., 1996a; Widjaja, Craske, \& Wootton, 1996b) and even during analysis (e.g., Buttery et al., 1983). The effect of sample preparation on 2-AP content in rice is covered in more detail in Part 7 of this review.

Soil and climate conditions during cropping can also influence 2-AP concentration in rice cultivars. During cultivation, a dry climate or sandy soil with low moisture retention can induce the fragrant rice cultivar Khao Dawk Mali 105 to produce more 2-AP (Yoshihashi et al., 2004). It appears that moisture during cultivation could be one of the most important factors affecting 2-AP formation when rice grows.

Due to the instability of 2-AP, drying and storage of rice can also influence the 2AP content of the final product (Wongpornchai et al., 2004). The unstable nature of 2AP will be discussed in detail in Part 6 of this review.

\subsection{Pandan}

2-AP is an important component of pandan leaf; the aroma of 2-AP is often described as pandan-like. Pandan plays an important role in south-east Asian cookery. The leaf of this plant is often boiled with rice to enhance flavour. When boiled with non-fragrant rice, it can provide the popcorn-like flavour associated with boiled fragrant rice, allowing cheap non-fragrant cultivars to possess similar aroma to higher value fragrant rice cultivars (Peter, 2006). The treatment of pandan leaf can affect 2AP content. The fresh or slightly withered leaf is normally torn into strips, tied in a bunch and then boiled together with rice. The pandan leaves are removed from the rice after cooking. 
The concentration of 2-AP in pandan leaves ranges from $40 \pm 10$ to $450 \pm 10$ $\mu \mathrm{g} / \mathrm{kg}$ (Yahya, Lu, Santos, Fryer, \& Bakalis, 2010). Dried and ground pandan leaves were extracted in this study. However, those treatments disrupted the papillae structure in epidermal cells on the surface of the pandan leaves. 2-AP is contained in the papillae; therefore, a proportion of 2-AP is lost during drying and grinding.

\subsection{Cereal products}

2-Acetyl-1-pyrroline has also been detected in cooked cereal-based products. Wheat bread crusts contain around $75 \mu \mathrm{g} / \mathrm{kg}$ 2-AP compared to $1-4 \mu \mathrm{g} / \mathrm{kg}$ in sourdough processed rye bread (Schieberle \& Grosch, 1987). Popcorn-like aroma compound 2-AP is, unsurprisingly, present in popcorn. However, in popcorn 2acetyltetrahydropyridine and 2-propionyl-1-pyrroline also contribute roasty and popcorn-like flavour. The alkyl side chains of those compounds are short; only one or two carbon atoms length. In contrast, 2-butanoyl-1-pyrroline and 2-hexanoyl-1pyrroline, compounds with similar structure but with longer alkyl side-chains, do not possess roasty or popcorn-like aroma (Schieberle, 1991).

2-AP was also identified in a cereal coffee brew at $8 \mu \mathrm{g} / \mathrm{L}$ and contributed intense popcorn-like odour attributes when analysed by gas chromatography-olfactometry (Majcher, Klensporf-Pawlik, Dziadas, \& Jeleń, 2013). The cereal coffee was a roasted mixture of $40 \%$ barley, $25 \%$ rye, $25 \%$ chicory, and $10 \%$ sugar beet.

\subsection{Other foods}

2-AP has also been detected in non-cereal-based food. A high concentration of 2- 
133

134

AP of up to $750 \mu \mathrm{g} / \mathrm{kg}$ was found on the surface of Mediterranean dried sausages, while values at the core were up to $100 \mu \mathrm{g} / \mathrm{kg}$. Penicillium nalgiovense, the dominant mould species present, was shown to synthesise 2-AP during sausage processing (Stahnke, 2000). Using gas chromatography-olfactometry (GC-O), Blank, Devaud, Fay, Cerny, Steiner, and Zurbriggen (2001) identified 2-AP as a key contributor to the aromas of both Parma ham and Italian-type salami. They described the compound as it eluted from the GC column as having a 'roasty' aroma in the Parma ham and a 'roasty, popcorn' aroma in the salami.

2-AP was also isolated in Manuka honey at concentrations of $80-450 \mu \mathrm{g} / \mathrm{kg}$. It was formed from methylglyoxal, which is responsible for the antibacterial activity in Manuka honey. Reaction of methylglyoxal with proline through the Strecker reaction can form 2-AP (Ruckriemen, Schwarzenbolz, Adam, \& Henle, 2015). In addition, 2AP was also isolated from two kinds of cooked edible fungus: huitlacoche and austern pilzen (Lizarraga-Guerra, Guth, \& Lopez, 1997), but the compound was mistakenly identified as 2-acetyl-2-pyrroline (Adams \& De Kimpe, 2006). The importance of 2AP in mushroom (Agaricus bisporus) aroma increased significantly as a result of panfrying (Grosshauser \& Schieberle, 2013), its concentration rising from 0.4 to 5.3 $\mu \mathrm{g} / \mathrm{kg}$. Similarly, 2-AP was also detected in both raw and roasted hazelnuts; a significant increase of 2-AP concentration was observed, from trace levels $(<3 \mu \mathrm{g} / \mathrm{kg})$ to $85 \mu \mathrm{g} / \mathrm{kg}$, when hazelnuts were roasted (Kiefl, Pollner, \& Schieberle, 2013).

2-AP may not always make a positive contribution to food aroma. An undesirable 'mousy' flavour in wetted raw pearl millet grits was attributed to 2-AP. Although 2- 
155

156

157

AP concentration was not quantified in this study, it was implied that there was a higher concentration of 2-AP in millet than in rice, which was reflected in the difference in their odour quality (Seitz, Wright, Waniska, \& Rooney, 1993).

2-AP has been identified and quantified in many food products. Table 2 shows those foods other than rice where 2-AP has been quantified. Even at a very low concentration, such as $3 \mu \mathrm{g} / \mathrm{kg}$ in milk chocolate (Liu, et al., 2015), this compound can still be considered a key odorant. In a recent review, a comprehensive list of food sources of 2-AP was provided, which included fruit and vegetables, fungi, cooked meat and fish, dairy and egg products (Wakte et al., 2016).

\subsection{2-AP as a flavouring}

Several patents have suggested that 2-AP could be applied as a food flavouring. A food coating with a content of at least $40 \mathrm{ppb} 2$-AP, made from fragrant rice, was applied to increase popcorn odour in several products (Richard, 2001). In distilled alcoholic beverages, 0.2 to $200 \mathrm{ppb}$ 2-AP contributed to a fragrant rice flavour (Asano et al., 2000). 2-AP was included in GRAS 22 (Smith et al., 2005) and the average and maximum levels for its addition to various food products have been summarised (Adams \& De Kimpe, 2006).

\section{Biological formation of 2-acetyl-1-pyrroline}

\subsection{Fragrant rice}

It was originally thought that 2-AP was only produced during the cooking of rice 
via the Maillard reaction (Buttery et al., 1982). However, further research has shown that 2-AP is produced by the rice plant, and is detected in the majority of plant tissues (Sakthivel, Sundaram, Rani, Balachandran, \& Neeraja, 2009; Sood \& Siddiq, 1978; Yoshihashi, Huong, \& Inatomi, 2002). It is now generally accepted that although some 2-AP in rice is produced during cooking, 2-AP is predominantly biosynthesised in rice.

Yoshihashi (2002) reported that 2-AP cannot be formed during the cooking of fragrant rice (when heated with or without water at $90{ }^{\circ} \mathrm{C}$ for $8,10,12,14 \mathrm{~min}$, the concentration of 2-AP showed a slight decrease), nor in postharvest processes like drying and storage. It can only be formed in the aerial parts of plants during growing in paddy fields. In a later paper by the same author, excised callus (cells covering a plant wound) and seedlings were floated on labelled amino acid (200 ppm ${ }^{15} \mathrm{~N}$ glycine, ${ }^{15} \mathrm{~N}$-L-proline or $1-{ }^{13} \mathrm{C}$-L-proline; $\left.\mathrm{pH} 5.5\right)$ solutions. After incubation at $27{ }^{\circ} \mathrm{C}$ in darkness for 8 hours, increasing 2-AP concentrations were detected. Results showed clearly that the labelled derivative was only found in seeding and callus incubated with ${ }^{15} \mathrm{~N}$-L-proline. This result indicated that one of the precursors in 2-AP biosynthesis could be proline but not glycine and that the nitrogen source of 2-AP is proline. On the other hand, because no labelled derivative was found in the $1{ }^{13} \mathrm{C}-\mathrm{L}-$ proline sample, the acetyl group in 2-AP could not be provided by proline (Yoshihashi, Huong, \& Inatomi, 2002).

It appears that moisture during cultivation could be one of the most important factors affecting 2-AP formation when rice grows. 2-AP concentrations in fragrant 
rice Khao Dawk Mali 105 from the Tung Kula Rong Hai region in north-east Thailand, where there is a drought-prone climate with sandy soil, were much higher than in the same rice grown in other areas of Thailand. Rice samples planted in clay soil can retain moisture during growth, resulting in lower 2-AP concentrations than those grown in sandy soil (Yoshihashi et al., 2004). Numerous studies have shown that proline accumulation occurs in higher plants due to different environmental stresses, such as drought, high salinity, high light and UV irradiation, heavy metals, oxidative stress and in response to biotic stresses (Szabados \& Savouré, 2010). For example, Rhodes, Handa, and Bressan (1986) showed that proline will accumulate in water-deficient plant cells through the glutamate pathway. In this study, tomato cells adapted to water stress induced with polyethylene glycol (PEG); a tenfold increase of proline synthesis was observed in the water-stressed cells. This research and that of Yoshihashi et al. (2004) suggest that more 2-AP will be synthesised when rice is grown in a dry climate, due to increased accumulation of its precursor proline.

In addition, a cool climate and early harvest could increase 2-AP concentration in fragrant rice varieties. Between 1992 and 1994, three brown fragrant rice cultivars from Japan (Hieri, Miyakaori and Sari Queen) were harvested once a year and their 2AP concentration was analysed. It was found that 2-AP was higher in rice crops exposed to low temperature (day $25^{\circ} \mathrm{C} /$ night $20^{\circ} \mathrm{C}$ ) than high (day $35^{\circ} \mathrm{C} /$ night $30{ }^{\circ} \mathrm{C}$ ) or moderate temperature (day $30{ }^{\circ} \mathrm{C} /$ night $25^{\circ} \mathrm{C}$ ). In addition, from results across three years, 2-AP concentrations of early harvest samples were higher than samples harvested at normal time (Itani, Tamaki, Hayata, Fushimi, \& Hashizume, 
In a recent study, a partial least squares model was built, based on planting and harvesting conditions, that could predict 2-AP concentrations in Thai Jasmine Pathumthani 1 rice (Funsueb, Krongchai, Mahatheeranont, \& Kittiwachana, 2016). The status of the rice plants was recorded during cultivation and after harvest, such as number of tillers (grain-bearing branches), plant height, root length, number of grains weight and number of tillers per plant all had significant influences on 2-AP concentration. substrate for the BADH2 enzyme (Oishi \& Ebina, 2005; Trossat, Rathinasabapathi, \& 
1-pyrroline (Struve \& Christophersen 2003), a 2-AP precursor. Hence the oxidation of 4-aminobutyraldehyde reduces the potential for 2-AP synthesis (Kovach, Calingacion, Fitzgerald, \& McCouch, 2009). Bradbury et al. (2005) identified a mutated version of the $B A D H 2$ gene as being responsible for determining fragrance in rice, which has since been confirmed (Arikit et al., 2011; Fitzgerald, Waters, Brools, \& Henry, 2010; Kovach et al., 2009; Siddiq, Vemireddy, \& Nagaraju, 2012). The mutated BADH2 gene incurs a deletion of eight base pairs in exon 7, leading to early gene termination and production of a truncated non-functional BADH2 enzyme (Bradbury et al., 2005). Non-fragrant rice cultivars contain the $B A D H 2$ gene and hence a functional BADH2 enzyme; whereas fragrant cultivars have the mutated $B A D H 2$ gene and so produce a non-functional enzyme (Bradbury, Gillies, Brusheet, Waters, \& Henry, 2008). This non-functional enzyme will not be able to oxidise 4-aminobutyraldehyde, leading to a build-up of 1-pyrroline and hence increased 2-AP synthesis. Recent studies have shown that there are various other mutations in the $B A D H 2$ gene that may also lead to increased 2-AP production, such as a deletion of seven base pairs in exon 2 (Amarawathi, Singh, Singh, Singh, Mohaoatra, \& Sharma, 2008; He \& Park, 2015). Similar biosynthetic pathways for the formation of 2-AP have been reported in soy beans (Arikit et al., 2011) and sorghum (Zanan, Khandagale, Hinge, Elangovan, Henry, \& Nadaf 2016).

Another biosynthetic pathway of 2-AP was proposed by Huang, Teng, Chang, Chuang, Ho, and $\mathrm{Wu}(2008)$ that did not involve BADH2. Higher levels of pyrroline5-carboxylate synthase enzyme, and hence increased conversion of glutamate to 1- 
pyrroline-5-carboxylate, occurred in fragrant cultivars, in comparison to non-fragrant cultivars. It was suggested that the 1-pyrroline-5-carboxylate undergoes a reaction with methylglyoxal, giving rise to $2-\mathrm{AP}$, either directly or via degradation to 1 pyrroline.

Although very different (a comparison can be seen in Figure 1), both pathways could require 1-pyrroline in order to produce 2-AP. 1-Pyrroline has been shown to be a limiting substrate of the biosynthesis of 2-AP in a recent study, where both fragrant and non-fragrant rice calli were incubated with 1-pyrroline. In both cases, a significant increase in 2-AP production was observed, proving 1-pyrroline to be a key intermediate of 2-AP biosynthesis (Poonlaphdecha et al., 2016).

\subsection{Formation of 2-AP by microorganisms}

Microorganisms could also play an important role in 2-AP formation. During cocoa bean fermentation, yeasts, lactic acid, acetic acid, and various spore-forming bacteria, such as Bacillus cereus, are involved in the flavour-forming reactions. Some Bacillus cereus strains produce popcorn-like notes and 2-AP was produced by several of these strains incubated on standard plate count agar at $35{ }^{\circ} \mathrm{C} ; 30-75 \mu \mathrm{g} / \mathrm{kg} 2-\mathrm{AP}$ was produced after 2 days. A series of ${ }^{13} \mathrm{C}$ and ${ }^{15} \mathrm{~N}$ experiments showed that 2-AP could be formed from glucose as carbon source, and glutamic acid and proline as nitrogen sources, through Bacillus cereus metabolism (Romanczyk, McClelland, Post, \& Aitken, 1995).

In Mediterranean dried sausages, which have a popcorn-like odour and are very 
different from Northern European sausages, 2-AP is also regarded as the key aroma compound. The main difference between Northern European sausages and Mediterranean dried sausages is a coverage of mould on the latter. 2-AP concentration on the surface of Mediterranean dried sausages is much higher than at the core. Therefore, it was suggested that the mould on the surface of Mediterranean dried sausages is able to produce 2-AP. Penicillium nalgiovense was isolated from the sausage surface and it was the dominating mould species. When incubated with and without various supplements, it was found that Penicillium nalgiovense could only produce popcorn odour when the sausage was present (Stahnke, 2000).

2-AP, together with other $N$-heterocyclic compounds 2-ethyltetrahydropyridine and 6-acetyl-1,2,3,4-tetrahydropyridine, could cause mousy off-flavour in wine (Herderich, Costello, Grbin, \& Henschke, 1995; Strauss \& Heresztyn, 1984), through the action of lactic acid bacteria (LAB). Lactobacillus hilgardii DSM 20176 was incubated with a defined $N$-heterocycle assay medium, which included D-fructose, ethanol, L-lysine, L-ornithine and mineral salts. It was found that L-ornithine stimulated 2-AP formation and repressed 6-acetyl-1,2,3,4-tetrahydropyridine formation, while L-lysine had the opposite effect (Costello \& Henschke, 2002). It had previously been suggested that $\mathrm{D}$-fructose and ethanol could provide the acetyl sidechain for 2-AP and 6-acetyl-1,2,3,4-tetrahydropyridine (Strauss \& Heresztyn, 1984). A possible mechanism of fermentable carbohydrate and amino acid, forming 2-AP and 6-acetyl-1,2,3,4-tetrahydropyridine through LAB fermentation was proposed by Costello and Henschke (2002). This pathway is shown in Figure 2. L-Lysine could 
form the intermediate 1-piperideine via cadaverine pathways, with the enzymes Llysine decarboxylase and cadaverine aminotransferase involved (Fothergill \& Guest, 1977). Pathways from putrescine to succinate via 1-pyrroline in P. fluorescens and E. coli (Jacoby \& Fredericks, 1959; Kim, 1964) have been reported. Putrescine is the decarboxylation product of ornithine (Fothergill \& Guest, 1977); hence, 1-pyrroline could be formed through the putrescine pathway from L-ornithine. Due to the presence of carbohydrates, such as ethanol and glucose/fructose, acetyl-CoA accumulated through the heterolactic pathway and reacted with intermediates 1pyrroline and 1-piperideine to form 2-AP and 6-acetyl-1,2,3,4-tetrahydropyridine , respectively.

Adams and De Kimpe (2007) reproduced the work of Romancyk et al. (1995) and suggested B. cereus formed 2-AP by enzymatic acetylation of 1-pyrroline. 1-Pyrroline was formed from the degradation of ornithine and proline, as proposed by Costello and Henschke (2002; see above and Figure 2).

\section{Formation of 2-acetyl-1-pyrroline through the Maillard reaction}

2-AP is not only present in raw food, like rice and pandan leaf, but is also formed in many cooked products. Therefore, the Maillard reaction is also an important route to 2-acetyl-1-pyrroline. Schieberle (1988) tested several model systems containing different amino acids, and showed that, when heated with reducing sugars, only proline, lysine and alanine could form 2-AP, with proline giving the highest yield. Two ${ }^{13} \mathrm{C}$-labelling experiments were designed: in the first experiment, $1-{ }^{13} \mathrm{C}$-proline 
reacted with unlabelled glucose, and in the second experiment, unlabelled proline reacted with $\mathrm{U}^{13} \mathrm{C}$-glucose (all six carbon atoms are labelled with ${ }^{13} \mathrm{C}$ ). Both experiments were carried out at $170{ }^{\circ} \mathrm{C}$ for $30 \mathrm{~min}$. In both experiments labelled carbon was only found in the acetyl group of 2-AP and much more ${ }^{13} \mathrm{C}$ was detected in the second experiment, which indicated that glucose could provide the acetyl group in 2-AP formation (Schieberle, 1988).

Schieberle (1990) showed that both proline and ornithine could react with 2oxopropanal to form 1-pyrroline, the most important intermediate in 2-AP formation, and there was a higher yield with ornithine than with proline. Figure 3a shows the formation of 1-pyrroline via Strecker degradation of ornithine; both ornithine and citrulline, another amino acid, can generate 4-aminobutanal. Schieberle (1995) also hypothesised a mechanism of 1-pyrroline formation from proline and 1-deoxyosone through Strecker degradation (Figure 3b). This reaction starts with the formation of an iminium ion. After decarboxylation and water elimination, 1-pyrroline can be generated from hydrolysis of the iminium ion.

Rewicki et al. (1993) reacted unlabelled proline with $1-{ }^{13} \mathrm{C}$-glucose, and noted the formation of a 1:1 mixture of unlabelled and labelled 2-AP. A proposed mechanism is shown in Figure 3c. Two isomers of 1-deoxy-2,3-glucosone form in a ratio of 1:1 from the labelled sugar. They are converted to the dihydro form of diacetylformoin, which reacts with 1-pyrroline, to form 2-acetylpyrrolidine, which then oxidises to 1:1 labelled and non-labelled 2-AP (Rewicki et al., 1993). The $1: 1{ }^{13} \mathrm{C}$ label was due to the 1:1 ratio of the reducing sugar fragments. The ${ }^{13} \mathrm{C}$ from labelled proline did not 
351

352

exist in the final 2-AP product; supporting the theory that 2-AP is formed by acylation of 1-pyrroline by a two-carbon sugar fragment. Hofmann and Schieberle (1998a) also reported that 2-acetylpyrrolidine could oxidise to 2-AP and proposed that 1-pyrroline and 2-oxopropanal formed 2-acetylpyrrolidine via a number of steps. 2Acetylpyrrolidine was then readily oxidised to 2-AP.

Phosphate ion could significantly increase the yield of 2-AP, through increased formation of 2-oxopropanal via 1,3-dihydroxyacetone phosphate (Schieberle, 1989). If malonate buffer replaced phosphate buffer, there was a one-third reduction of 2-AP formation (Schieberle, 1995). Blank, Devaud, Matthey-Doret, and Robert (2003) examined the effect of $\mathrm{pH}$ and heating time on the formation of various Maillardderived compounds in two phosphate-buffered model systems: one an equimolar mixture of proline and glucose, the other the Amadori compound fructose-proline. 2AP yield was similar in both systems across all treatments and was shown to increase with increasing $\mathrm{pH}$ and heating time, when samples were refluxed for 1, 2 and 4 hours at $\mathrm{pH} 6,7$ and 8.

From the above hypothesised mechanisms of 2-AP thermal formation, it is agreed that 2-AP is formed through an acylation of 1-pyrroline. Certain amino acids, i.e., proline, ornithine and citrulline, reacting with 2-oxpropanal from reducing sugar fragmentation, are the most important intermediates of 2-AP formation during the Maillard reaction (Adams \& De Kimpe, 2006).

\section{Synthesis of 2-acetyl-1-pyrroline}


The first synthesis of 2-AP was reported by Buttery et al. (1983) and is shown in Figure 4a. This method is based on an earlier synthesis of a six-membered ring compound 2-acetyl-1,4,5,6-tetrahydropyridine (Buchi \& Wuest, 1971). However, the yield of 2-AP from this reaction was only around $10 \%$.

The first large-scale method for 2-AP synthesis was developed in 1993. Methyl prolinate is oxidised to 2-(methoxycarbonyl)-1-pyrroline, which then reacts with methylmagnesium iodide in a Grignard reaction. However, this is not a completed reaction with a $45-83 \%$ yield and $8-39 \%$ starting material in the final product (De Kimpe, Stevens, \& Keppens, 1993). Methyllithium in ether also converted 2(methoxycarbonyl)-1-pyrroline into a mixture of 2-acetyl-1-pyrroline (47\%) and a side-product, 2-(1-hydroxy-1-methylethyl)-1-pyrroline (32\%) (Fig. 4b). To prevent formation of this side-product, which was also formed in the methylmagnesium iodide reaction, a cyanide functional group can replace the ester (Figure 4c). In this modified method, the reaction started with oxidation of pyrrolidine to tripyrroline. The tripyrroline was hydrocyanated into 2-cyanopyrrolidine, which can form 2-cyano-1pyrroline through the Grignard reaction. 2-Cyano-1-pyrroline can form 2-AP with a yield of $60 \%$ when treated with methylmagnesium iodide (De Kimpe et al., 1993).

Over subsequent years, other synthesis methods focused on the stabilisation of 2AP during the reaction, by using protected carbonyl groups, e.g., Duby and Huynh-Ba (1993), or amino groups, e.g., De Kimpe and Keppens (1996). De Kimpe and Keppens (1996) used diacetyl as a starting material to generate an $\alpha$-diimine, which then reacted with a stabase derivative to form the 1-pyrroline ring structure (Fig. 4d). 
395

396

397

398

399

400

401

402

403

404

405

406

407

408

409

410

411

412

413

414

415

Another synthesis method applied the high substrate selectivity of immobilised penicillin G acylase (PGA) as the catalyst in the last reaction step (Favino, Fronza, Fuganti, Fuganti, Grasselli, \& Mele, 1996). 1-Aminohex-4-yne reacted with phenylacetyl chloride, and then ozone oxidised the product to form 1-[N(phenylacetyl)amino]-4,5-dioxohexane, which when treated with PGA could form 2AP spontaneously, as shown in Figure 4e. An $80 \%$ yield of 2-AP could be achieved using this method.

A four-step synthesis was reported by Hofmann and Schieberle (1998b) starting from $N$-tert-butoxycarbonyl-protected proline, while 2-pyrrolidinone was selected as a raw material for 2-AP synthesis by Harrison and Dake (2005). Another 'popcorn' compound, 2-acetyl-1,4,5,6-tetrahydropyridine, was a by-product of this latter method. A three-step synthesis was reported by Fuganti, Gatti, and Serra (2007), starting from the reaction of $N$-Boc-pyrrolidinone with ethylmagnesium bromide. The yield of 2-AP was only 20-30\% but with 98\% purity. Maraval et al. (2010) formed N,5-diacetylpyrrolidin-2-one from L-glutamic acid and acetic anhydride with 78\% yield. Sodium carbonate was used for deacetylation to form 5-acetylpyrrolidin-2-one; then lithium aluminium hydride was used for reduction to form 2-(1-hydroxyethyl)pyrrolidine, which was oxidised by silver carbonate to 2 -AP. The overall yield of 5 acetylpyrrolidin-2-one formation was 37\% but the yield of 2-AP was not reported.

A recent publication reported the synthesis of three major popcorn-like Maillard aroma compounds, 2-acetyl-1-pyrroline, 2-acetyl-1,4,5,6-tetrahydropyridine and 2acetyl-5,6-dihydro-4H-1,3-thiazine (Deblander, Van Aeken, Adams, De Kimpe, \& 
Abbaspour Tehrani, 2015). The authors noted that existing synthetic procedures for these compounds suffered a number of problems, including extensiveness of some reaction pathways, and the use of costly and/or harmful reagents. The 2-AP synthesis they proposed started from $N$-Boc-prolinate to give a final yield of 2 AP of $28 \%$, via a four-step reaction (Fig. 4f). The authors considered this method to be relatively straightforward, as the starting materials were readily available, only one general procedure was involved and the vinyl ether intermediate prepared was a stable precursor, which could be readily converted to 2-AP.

Although numerous procedures have been published for the synthesis of 2-AP, these methods all require an experienced organic chemist to make them work. Synthesis of 2-AP is difficult, due to the unstable nature of this compound, which degrades very rapidly upon standing (see Part 6). This is reflected in the high price of commercial 2-AP and the small number of 2-AP suppliers.

\section{Stability and stabilisation of 2-acetyl-1-pyrroline}

Stability is very important for a flavour compound in food products. Unfortunately, 2-acetyl-1-pyrroline has limited stability. Pure 2-AP will turn red and degrade within $10 \mathrm{~min}$ at room temperature (Fang \& Cadwallader, 2014). This instability of 2-AP was noticed when it was first identified by Buttery et al. (1982), and this instability was assumed to be due to polymerisation. Loss of 2-AP in stored foods could be due to complexation, decomposition, diffusion to the environment and 
generation of other compounds (Adams \& De Kimpe, 2006).

An experiment was designed to investigate the effect of storage on 2-AP levels in rice (Widjaja et al., 1996a). In this experiment, using the fragrant cultivar YRF9, paddy (rice with husk and rice bran), brown (rice without husk but with rice bran) and white (rice without husk and rice bran) rice samples were stored under two conditions: atmospheric pressure and reduced pressure, at $84 \% \mathrm{RH}$ and $30^{\circ} \mathrm{C}$. After three months' storage, 2-AP level was reduced by $40-50 \%$ in all cases. Another study aimed to compare the effect of different drying methods and storage time on 2-AP reduction in fragrant rice (Wongpornchai et al., 2004). Six different drying methods (sun drying, $30{ }^{\circ} \mathrm{C}$ modified air, $40{ }^{\circ} \mathrm{C}$ modified air, $40{ }^{\circ} \mathrm{C}$ air, $50{ }^{\circ} \mathrm{C}$ air and $70{ }^{\circ} \mathrm{C}$ air) were applied to fresh paddy rice, to reduce moisture content from $28 \%$ to below $14 \%$, and then the rice was stored in gunnysacks at $20-35^{\circ} \mathrm{C}$. 2-AP concentration in 10 months stored rice was only $25 \%$ of freshly dried rice and it was shown in a concentrationstorage time curve that a significant decrease occurred at the beginning of storage. The sun-dried sample retained less 2-AP than the other drying methods; this could be due to the longer drying time. Sun drying took 54 hours in this study, while the average time for the other drying methods was 10 hours. Although the authors did not provide details of the modified air used, drying with this kind of air maintained 2-AP in rice better than normal hot air drying, while lower air temperatures also resulted in less 2-AP loss (Wongpornchai et al., 2004).

In addition to rice, 2-AP decreases in other food products during storage. Hot air popped popcorn was sealed in commercial polyethylene food bags and stored in the 
dark at room temperature. After two days, the 2-AP level reduced by $20 \%$ and after seven days storage, it reduced by $75 \%$ (Schieberle, 1995).

Therefore, it is important to develop a stabilisation method to defer 2-AP breakdown. Encapsulation is a popular technique to protect unstable volatile compounds for commercial processing, and several studies have applied this technique. Encapsulation of 2-AP by $\beta$-cyclodextrin (Duby \& Huynh-Ba, 1996) showed some success. When stored at room temperature $\left(20{ }^{\circ} \mathrm{C}\right), 99 \% 2$-AP decomposed after 110 days' storage, when the 2-AP load of the $\beta$-cyclodextrin was $1 \%$. However, if the storage temperature decreased, encapsulation performed better, with $10 \%$ losses at $4{ }^{\circ} \mathrm{C}$ and no losses at $-20{ }^{\circ} \mathrm{C}$. If the loading of cyclodextrin was increased to $10 \%$, the stability of the 2 -AP was reduced.

Apintanapong and Noomhorm (2003) extracted 2-AP from pandan leaves and examined its stability at $30 \mathrm{ppm}$ in acidic and basic solution at room temperature. They alaso microencapsulated 2-AP in various maltodextrin and gum acacia mixtures. In basic solution, 2-AP was reduced by $63 \%$ after 7 days, and in acidic solution by $30 \%$ after 35 days. When 2-AP was microencapsulated with 70:30 gum acacia:maltodextrin, only $28 \%$ of the encapsulated 2-AP was lost after 72 days at room temperature. Gum acacia and/or starch mixed materials were used in a patented form by Srinivas, Sulochanamma, Raghavan, and Gurudutt (2006), to form a stable 2AP powder using spray drying, but the stability of this powder was not reported. Fang and Cadwallader (2014) recently reported a novel stabilisation method, using zinc ions to solve 2-AP powder storage problems. Anhydrous 2-AP and $\mathrm{ZnI}_{2}$ were 
added into diethyl ether to form a yellowish precipitate, which was the desired 2-AP$\mathrm{ZnI}_{2}$ complex. Excess $\mathrm{ZnI}_{2}$ and other impurities were removed through dissolving the complex in anhydrous diethyl ether. The complex compound was obtained as a powder after drying through nitrogen evaporation. Other 2-AP-zinc halide complexes could be obtained in the same way. When stored at $25{ }^{\circ} \mathrm{C}$, there was only $6 \%$ loss of 2-AP from a $2-\mathrm{AP}-\mathrm{ZnI}_{2}$ complex $(2-\mathrm{AP}$ content $=14.4 \%)$ after 3 months, and $3 \%$ reduction of 2-AP after 3 months when a 12.5\% 2-AP content complex was stored at $20{ }^{\circ} \mathrm{C}$. It was found that compared with $\mathrm{ZnI}_{2}$ (2-acetyl-1-pyrroline) $)_{\mathrm{n}}$, which had a yield of $62 \%$, complexes of $\mathrm{ZnBr}_{2}$ (2-acetyl-1-pyrroline) $)_{\mathrm{n}}$ and $\mathrm{ZnCl}_{2}$ (2-acetyl-1-pyrroline) ${ }_{\mathrm{n}}$ had better yields of $96 \%$ and $86 \%$, respectively. $\mathrm{A} \mathrm{ZnCl}_{2}-2-\mathrm{AP}$ complex would be the preferred food agent because $\mathrm{ZnCl}_{2}$ has been approved for food use (CFR - Code of Federal Regulations Title 21; April $1^{\text {st }}$,2016). This method can also applied to similar volatile compounds, such as 2-propionyl-1-pyrroline, 2-acetyl-1,4,5,6tetrahydropyridine, 2-acetyl-2-thiazoline, 2-acetylthiazole, 2-acetylpyrazine and 2acetylpyridine. Although this is an effective technique for 2-AP stabilisation compared with others, this high yield was only confirmed in the dry powdered complex. It may be reduced by moisture, temperature and other conditions when applied in food. Therefore, it may be necessary to combine this technique with an encapsulation technique to protect the 2-AP-zinc halide complex in a changeable food environment (Fang \& Cadwallader, 2014).

\section{Extraction and instrumental analysis of 2-acetyl-1-pyrroline}




\subsection{Solvent-based extraction techniques}

Simultaneous distillation extraction (SDE) was used as the extraction method when 2-AP was first discovered by Buttery et al. (1982). SDE was widely used in the 1980s and 1990s for volatile compound extraction (Chi, Yeung, \& MacLeod, 1981). The sample is heated in water to produce steam and the steam transfers volatile material to a boiling non-polar solvent, which condenses to give an aroma extract (Likens \& Nickerson, 1964). However, this vigorous heating process may cause volatile compound formation or breakdown. Buttery et al. (1983) reported that the boiling conditions used in this extraction may decompose 2-AP in rice and cause a lower concentration than in raw samples.

In Buttery's study, $500 \mathrm{~g}$ rice were extracted with $6 \mathrm{~L}$ water in a Likens-Nickerson type extraction equipment (Likens \& Nickerson, 1964); diethyl ether was used as solvent and the isolation process was carried out at atmospheric pressure for 2 hours. After concentration, the solvent extract was dissolved in hexane and then extracted with $3 \mathrm{~N}$ hydrochloric acid and then ether. The ether extract was then concentrated to a small amount for analysis. For subsequent quantitative measurements (Buttery, Ling, \& Mon, 1986), an internal standard (5 mL of $30 \mathrm{ppm} \mathrm{2,4,6-trimethylpyridine}$ (collidine) solution) was added to the rice before extraction. Buttery's group published a number of papers on 2-AP in fragrant rice. They detected 2-AP in 10 different varieties of cooked rice (both milled and brown) using SDE and found that the concentrations of 2-AP in brown rice were much higher than in white rice (Buttery et al., 1983). 

following decade for 2-AP extraction in rice, pandan leaf and other food samples. Addition of magnesium sulfate $\left(\mathrm{MgSO}_{4}\right)$ during rice $\mathrm{SDE}$ inhibited starch gelatinisation, water absorption, swelling of rice and foaming of the mixture during distillation (Widjaja et al., 1996a \& b). Dichloromethane (DCM) has also been used as the extraction solvent in SDE of 2-AP (Nadaf, Krishnan, \& Wakte, 2006). were compared, samples were boiled during the SDE process (Widjaja et al., 1996a \& b). When white Italian Line B5-3 and basmati, two fragrant rice species, were compared, they were also boiled during SDE. A 4-fold higher 2-AP concentration was found in the Italian variety than in basmati (Tava \& Bocchi, 1999). Several different varieties of brown fragrant rice (Malagkit Sungsong, 370 basmati, Khashkani and Indica) were boiled for $25 \mathrm{~min}$ in tap water before SDE analysis. 2-AP was found in

540 all four species but the concentration in Indica was much lower than in the others (Jezussek, Juliano, \& Schieberle, 2002). 2-AP was also detected in five boiled fragrant rice cultivars; four of them were white rice (Hyangmibyeo 1, Hyangmibyeo 2, Royal, Golden Elephant) and one a Korean black rice called Goemjeongssal. Boiled non-

544 fragrant rice Jeongilpum also contained 2-AP. Those six cultivars were boiled $30 \mathrm{~min}$ 545 with distilled water (Yang, Shewfelt, Lee, \& Kays, 2008). Three white fragrant 546 cultivars (Aychade, Fidji, and Giano) and one white non-fragrant cultivar (Ruille) were boiled for $20 \mathrm{~min}$. 2-AP was found in all four cultivars, but the concentration in 
548

549

550

551

552

553

554

555

556

557

558

559

560

561

562

563

564

Ruille was too low to quantify; it was lower than $2 \mu \mathrm{g} / \mathrm{kg}$ while the concentrations in the other fragrant cultivars were $150-300 \mu \mathrm{g} / \mathrm{kg}$ (Maraval et al., 2008).

When using SDE at atmospheric pressure, sample and water mixture are boiled. Therefore, this kind of extraction technique cannot be used to study uncooked foods. Buttery et al., when first identifying 2-AP, used simultaneous distillation/extraction under vacuum (V-SDE) to study rice aroma. However, compared to SDE at atmospheric pressure (A-SDE), V-SDE showed a low efficiency of extraction (Buttery et al., 1983). Levels of 2-AP in rice extracted by A-SDE were 10 times higher than in rice that was cooked and then extracted with V-SDE. The authors suggested that most of the 2-AP may be lost during cooking. Therefore, compared with A-SDE, where rice is cooked during the isolation process, less 2-AP is present in the already cooked sample in V-SDE. In addition, 2-AP may be generated during cooking, which can also cause the significant difference in concentrations obtained between V-SDE and A-SDE.

Another solvent-based extraction technique, solvent-assisted flavour evaporation (SAFE), first introduced in 1999 (Engel, Bahr, \& Schieberle, 1999), is a useful technique for 2-AP extraction. The volatile compounds in a solvent extract, usually in diethyl ether or dichloromethane, are removed from non-volatile material using highvacuum distillation. The procedure takes place at around $30{ }^{\circ} \mathrm{C}$, keeping sample decomposition to a minimum. When using 1:1 diethyl ether:dichloromethane as the solvent, 2-AP was isolated from cereal coffee brew (Majcher et al., 2013) and this compound was also isolated from hazelnut when using diethyl ether as solvent (Kiefl 
et al., 2013).

commercial SPE cartridges (Strata ${ }^{\mathrm{TM}} \mathrm{X}$ from Phenomenex, LiChrolut ${ }^{\circledR}$ EN from Merck Millipore and Isolute ${ }^{\circledR}$ ENV+ from Biotage) have been successfully used for volatile compound extraction (Du \& Qian, 2008; Metafa \& Economou, 2013), particularly for isolation of relatively polar aroma compounds, such as 2-AP. An advantage of SPE is that no heating is applied when using this technique, which is the same as SAFE, but SPE is much easier to perform than SAFE. 2-AP was generated during high-temperature cooking of fragrant rice $\left(180{ }^{\circ} \mathrm{C}\right.$ for $20 \mathrm{~min}$ in an open system), using SPE, followed by GC-MS (Handoko, 2014). This result suggests that there may be a component of fragrant rice that is formed enzymatically, which can be converted to 2-AP by the application of higher temperatures. Although there was no 2AP detected in Ciherang rice (a non-fragrant rice) heated under the same conditions, a sensory panel perceived popcorn-like odour (Handoko, 2014), suggesting that compounds besides 2-AP that could cause popcorn-like odour in rice heated at $180{ }^{\circ} \mathrm{C}$.

\subsection{Headspace techniques}

Dynamic headspace extraction using an adsorbent polymer such as Tenax can also be used in 2-AP extraction, Buttery, Turnbaugh, and Ling (1988) used this technique to analyse the volatile compounds in cooked rice. Seventeen volatile compounds include 2-AP were identified through this method. Around $0.6 \mu \mathrm{g} / \mathrm{kg} 2-\mathrm{AP}$ were found in white Californian long-grain rice (a kind of non-fragrant rice) boiled in water for 20 
592

593

594

595

596

597

598

599

600

601

602

603

604

605

606

607

608

609

610

611

612

613

min before Tenax trapping (Buttery et al., 1988). Around 30 odorants were identified in cooked rice using the same technique (Yang et al., 2008).

Headspace solid-phase microextraction (HS-SPME) is now the most widely used extraction method for 2-AP. As with all extraction techniques, increased extraction time or higher temperatures could result in better release of 2-AP from the sample. However, the reported instability of 2-AP may cause its loss during isolation at higher temperatures, while at lower temperatures enzymatic changes may occur during this extraction. These conflicting reactions make 2-AP quantification difficult.

One large study used manual SPME to analyse 91 different uncooked cultivars, including 77 non-basmati fragrant cultivars, 9 basmati fragrant cultivars and 5 nonfragrant cultivars. A 1-cm divinylbenzene/Carboxen/polydimethylsiloxane (DVB/CAR/PDMS) fibre was used in this experiment. Samples were extracted for 15 min at $80{ }^{\circ} \mathrm{C}$ after a 30-min equilibration period. 2-AP was detected in some nonfragrant cultivars but its average concentration was around 10 -fold higher in basmati fragrant cultivars and around 20-fold higher in selected non-basmati fragrant cultivars (Mathure, Wakte, Jawali, \& Nadaf, 2011; Mathure, Jawali, Thengane, \& Nadaf, 2014). Bryant and McClung (2011) used an automated SPME system to compare seven uncooked fragrant and two uncooked non-fragrant rice samples extracted with a 1-cm DVB/CAR/PDMS SPME fibre at $80{ }^{\circ} \mathrm{C}$ for $18 \mathrm{~min}$ after a 5 -min equilibration period. 2-AP was only found in the fragrant rice samples.

A recent study measured 2-AP in 48 fragrant rice samples using manual SPME, followed by GC-MS/MS. The ion transition from $\mathrm{m} / \mathrm{z} 111$ to $\mathrm{m} / \mathrm{z} 82$ was used to 
614

615

quantify 2-AP. Optimised conditions were 10 minutes extraction at $40{ }^{\circ} \mathrm{C}$ after a 5 min thermostatting period. The technique was sensitive enough both to quantify 2 -AP below its odour threshold concentration (Buttery et al., 1983) and to obtain successful 2-AP measurements using a single grain of rice (Hopfer et al., 2016). Although DVB/CAR/PDMS fibres performed better than DVB/PDMS fibres, the latter were preferred, because carry-over (the presence of volatile material from the fibre in a subsequent blank analysis) observed when using the DVB/CAR/PDMS fibre was not observed with the DVB/PDMS fibre. A limit of quantification of $103 \mathrm{ng}$ per $\mathrm{kg}$ was reported for 2-AP in this work.

\subsection{Gas chromatography-mass spectrometry}

Gas chromatography-mass spectrometry (GC-MS) is the most common technique used for volatile compound analysis. Column choice in GC-MS analysis of 2-AP is very important. A polar phase (e.g., Carbowax) is normally chosen; 2-AP is a relatively polar compound and its peak shape is more symmetrical and sharper on a polar column. The use of base-deactivated phases is recommended for basic compounds that may possess poor peak shape under normal GC conditions (De Zeeuw, Stricek, \& Stidsen, 2011). A base-deactivated column may also be useful for quantifying 1-pyrroline (Poonlaphdecha et al., 2016). Because of the instability of 2AP, Buttery et al. (1986) recommended a relatively low injector temperature of 150$170{ }^{\circ} \mathrm{C}$ to minimise its decomposition. Base-deactivated injection port liners may also have a protective role (De Zeeuw et al., 2011). 
636

637

is a common challenge. This interference problem was first reported by Paule and Powers (1989) when using a packed column coated with 10\% Carbowax 20M on Chromosorb ${ }^{\circledR} \mathrm{W}$; 1-hexanol eluted very close to 2-AP and could interfere in its quantification. The mass spectrum of 6-methyl-5-hepten-2-one contains all the major ions present in the mass spectrum of 2 -AP $(\mathrm{m} / \mathrm{z} 43,41,111,83,68,69)$; these two compounds often co-elute in fragrant rice extracts run on polar columns, affecting the quantification of 2-AP, especially when the concentration of 2-AP is similar to or lower than that of 6-methyl-5-hepten-2-one. A long isothermal stage of $65{ }^{\circ} \mathrm{C}$ for 70 min at the start of the GC run was reported by Tanchotikul and Hsieh (1991) when performing sample analysis by GC-MS using a 60-m length Supelcowax ${ }^{\circledR} 10$ (Supelco, Bellefonte, PA) column. A similar method was reported by Seitz et al. (1993), to obtain better separation of 2-AP and 6-methyl-5-hepten-2-one. They used a shorter, $30 \mathrm{~m}$ Supelcowax 10 column in this analysis at an initial temperature of $60^{\circ} \mathrm{C}$ for $15 \mathrm{~min}$.

Although electron ionisation (EI) is the usual ionisation mode used for GC-MS, chemical ionisation (CI) is an option. CI is a softer ionisation technique, which can reduce interference during MS analysis compared with EI, and hence could result in increased signal-to-noise ratio for compounds of interest. In a study on bread flavour by Schieberle and Grosch (1987), 2-AP was analysed in CI mode using isobutane as reagent gas. Compared with EI mode in GC-MS analysis, Maraval et al. (2010) reported that positive ion CI mode could be better for 2-AP quantification in rice, especially when MS-MS was applied for analysis. The EI mass spectrum of 2-AP 
658

659

660

661

662

663

664

665

666

667

668

669

670

671

672

673

674

675

676

677

678

679

possesses few defining peaks: a characteristic ion at $\mathrm{m} / \mathrm{z} 83$ and a less intense molecular ion at $m / z$ 111. However, in PCI mode, using acetonitrile as the reagent gas, only an intense pseudomolecular ion at $m / z 112$ was observed. Under MS-MS conditions, $\mathrm{m} / \mathrm{z} 112$ ion yielded a fragment ion at $\mathrm{m} / \mathrm{z} 70$ and this transformation was used for 2-AP quantification, with a low limit of quantification of $0.4 \mu \mathrm{g} / \mathrm{kg}$.

\subsection{Quantification of 2-acetyl-1-pyrroline}

When Buttery et al. (1983) first quantified 2-AP in rice they measured peak areas by flame ionisation detector and performed an approximate quantification, in order to determine the relative amounts of 2-AP in the 16 types of rice that they analysed. In subsequent work they used collidine (2,4,6-trimethylpyridine) as an internal standard, adding it in solution to the rice/water mixture prior to extraction. Collidine was chosen because it has similar physicochemical properties to 2-AP (basic, similar water solubility, similar volatility), is stable, has a GC retention time similar to $2-\mathrm{AP}$ on a wax column and is commercially available (Buttery et al., 1986). Known amounts of 2-AP were added to the rice prior to extraction alongside a fixed amount of collidine, in order to provide a calibration curve for quantification. Collidine was subsequently used as the internal standard in a number of papers where 2-AP was quantified in rice (Tanchotikul \& Hsieh, 1991; Widjaja, et al. 1996a \& b; Tava \& Bocchi, 1999; Bergman et al., 2000).

Stable isotope dilution assays (SIDA) are now widely used in flavour science. An isotopomer of the compound of interest is added to the sample under study, in order to permit accurate quantification of the compound of interest. The quantification of 2-AP 
680

681

682

683

684

685

686

687

688

689

690

691

692

693

694

695

696

697

698

699

700

701

by SIDA was carried out for the first time by Schieberle and Grosch (1987). They prepared a 2-AP analogue, which was partially deuterated in the heterocyclic ring, giving a product with a range of molecular masses from 113 to 116 . They then used the deuterated isotopomer to quantify 2 -AP in wheat and rye bread.

SIDA was used to measure 2-AP in rice for the first time by Yoshihashi et al. (2004). Instead of deuteration, a ${ }^{13} \mathrm{C}$ atom was introduced in the methyl position of the acetyl side-chain giving an isotopomer with a mass of 112. Naturally-occurring 2-AP has an $\mathrm{M}+1$ ion with a mass of 112 , which has $7 \%$ of the intensity of its molecular ion. It is not clear if this was taken into account by the authors in their calculations. This issue was highlighted by Maraval et al. (2010), who used SPME with deuterated 2-AP to quantify 2-AP in rice. Unlike Schieberle and Grosch (1987), the deuteration was defined. Deuterium-hydrogen exchange can occur in aqueous solution and to reduce the chances of this happening the authors replaced both hydrogen atoms at the 5-position of the heterocyclic ring with deuterium. In order to provide a calibration curve for quantification, ground leaves from a non-scented rice cultivar were spiked with nine different amounts of 2-AP in solution.

The key reason for performing SIDA is that several steps of enrichment of the compounds can be performed without losses in accuracy, provided that the initial ratio between the compound and its labelled analogue remains unchanged during the entire procedure (Schieberle \& Grosch, 1987). As the compound of interest and its isotopomer should have the same physicochemical properties, SIDA provides a degree of confidence that is lacking when other internal standards are used. The incompletely 
deuterated 2-AP synthesised by Schieberle and Grosch is now available commercially from AromaLab AG (Planegg, Germany) and has been used to quantify 2-AP in rice (Hopfer et al., 2016).

\section{Sensory evaluation of 2-acetyl-1-pyrroline}

2-AP is described as a popcorn-like odour compound and it has a very low odour threshold. When Buttery et al. (1983) first identified this compound, they ranked the amount of popcorn-like odour in different rice varieties. Malagkit Sungsong, a kind of Philippine fragrant rice, had the greatest popcorn aroma and Texas Long Grain was determined as the rice with the least popcorn aroma. The most famous fragrant rice, basmati, was ranked in the middle of this list. When the Malagkit Sungsong was compared with Calrose (a non-fragrant rice), it was easy to distinguish them. However, when a 2-AP solution was added to the Calrose rice, they became much more difficult to tell apart. It was clear that the popcorn aroma of 2 -AP is a key component of rice flavour.

Lexicons of aroma and flavour of rice are being continuously developed by researchers (Goodwin et al., 1996; Piggott, Morrison, \& Clyne, 1991; Yau \& Liu, 1999). When comparing these studies, some descriptors are similar, but some are different; it is difficult to estimate which research has an intact lexicon and which needs more development. The choice of descriptors depends on the culture and familiarity with the sample of the panellists in each study (Paule \& Powers, 1989). A study aiming to build an intact lexicon tested 36 different varieties of rice, which were 
mainly jasmine and basmati rice samples from different regions, but also included many other fragrant and non-fragrant rice species (Limpawattana \& Shewfelt, 2010). Twenty-four attributes were listed by 8 trained panellists, of which 6 did not vary across the 36 varieties. The 18 attributes finally used in this study were 'popcorn', 'starchy', 'woody', 'cooked-grain', 'grain', 'sulfury', ‘corn', 'nutty', 'floral', 'dairy’, 'hay-like', 'barny', 'buttery', 'green', 'rancid', 'waxy', and 'earthy'. A standard and intensity of standard for each attribute was also defined. Of the 18 significant attributes, 'popcorn', which was mainly attributed to 2-AP, was positively correlated with 'buttery' and 'corn' and negatively correlated with 'earthy' and 'smoky'.

In an earlier study from Limpawattana's group, sensory profiling was conducted on 13 varieties of rice by using trained panels, and aroma-active compounds were analysed by GC-olfactometry (GC-O) and GC-MS (Limpawattana, Yang, Kays, \& Shewfelt, 2008). In this study, a predictive model was built for correlation analysis of attributes and volatile compounds. Unexpectedly, 'popcorn' in this model was negatively correlated with guaiacol and (E,E)-2,4-decadienal, while 2-AP was not present in this model as a 'popcorn' descriptor. Guaiacol and (E,E)-2,4-decadienal contributed smoky and fatty attributes, respectively. The authors suggested that the thermal process of reference standard preparation may have influenced the 'popcorn' descriptor analysis. In addition, these authors suggested that the contribution of 2-AP to popcorn-like odour was always overemphasised relative to many other compounds which also contribute to this aroma in fragrant rice.

Three types of fragrant rice (jasmine, basmati, and Jasmati) were studied in a 
recent paper, to compare their main aroma active compounds using GC-O and GCMS (Mahattanatawee \& Rouseff, 2014). Hexanal, octanal, 2-AP, (E,E)-2,4nonadienal, (E)-2-nonenal, 4-vinyl-2-methoxyphenol and indole were identified as the aroma-active compounds common to all three species. Across all three types of rice, 30 compounds were identified as aroma-active compounds and were described by 8 attributes. Jasmati contained 35\% less 'roasty/nutty' total aroma intensity than jasmine and basmati, while 'medicine' flavour was not detected in jasmine rice. Jasmine contained 35\% more 'sweet fruity/floral' total intensity than basmati and 79\% more than Jasmati.

\section{Conclusions}

2-AP contributes important aroma in many foods, like pandan leaf, mushroom and especially fragrant rice. Amino acids, in particular proline and ornithine, have been identified, alongside reducing sugars, as precursors of 2-AP in both biosynthesis and Maillard reaction. The presence of a non-functional betaine aldehyde dehydrogenase (non-functional BADH2) allows the formation of 2-AP in fragrant rice and several bacteria like Bacillus cereus and Penicillium nalgiovence may also form 2-AP.

It appears that 1-pyrroline is a key intermediate in both biosynthesis and thermal formation of 2-AP, and this intermediate could form 2-AP through an acylation reaction. 2-Oxopropanal and 2-acetylpyrrolidine are other intermediates hypothesised to form 2-AP during the Maillard reaction and the presence of phosphate ion could increase yields of 2-AP. 2-AP formation mechanisms, particularly in rice, still need to 
be researched. The work of Poonlaphdecha et al. (2016) showed the importance of 1-

769 pyrroline in 2-AP formation, and future work with this intermediate may provide 770 useful information.

771 Synthesis of 2-AP is still difficult but its stabilisation in a zinc halide complex has

772 increased its applicability. New synthesis strategies and stabilisation techniques could

773 reduce the cost of 2 -AP, which may increase its use in the food industry, adding

774 desirable popcorn-like aroma to rice products such as rice cakes. Another possibility 775 is the addition of 2-AP intermediates, such as 1-pyrroline, to rice, which can then 776 readily form 2-AP during processing, providing a desirable fragrance to rice products. 


\section{References:}

Adams, A., \& De Kimpe, N. (2006). Chemistry of 2-acetyl-1-pyrroline, 6-acetyl1,2,3,4-tetrahydropyridine, 2-acetyl-2-thiazoline, and 5-acetyl-2,3-dihydro4H-thiazine: Extraordinary Maillard flavor compounds. Chemical Reviews, 106(6), 2299-2319.

Adams, A., \& De Kimpe, N. (2007). Formation of pyrazines and 2-acetyl-1-pyrroline by Bacillus cereus. Food Chemistry, 101(3), 1230-1238.

Amarawathi, Y., Singh, R., Singh, A. K., Singh, V. P., Mohaoatra, T., \& Sharma, T. R. (2008). Mapping of quantitative trait loci for basmati quality traits in rice (Oryza sativa L.). Molecular Breeding, 21(1), 49-65.

Apintanapong, M., \& Noomhorm, A. (2003). The use of spray drying to microencapsulate 2-acetyl-1-pyrroline, a major flavour component of aromatic rice. International Journal of Food Science and Technology, 38(2), 95-102.

Arikit, S., Yoshihashi, T., Wanchana, S., Uyen, T. T., Huong, N. T. T., Wongpornchai, S., \& Vanavichit, A. (2011). Deficiency in the amino aldehyde dehydrogenase encoded by GmAMADH2, the homologue of rice Os2AP, enhances 2-acetyl1-pyrroline biosynthesis in soybeans (Glycine max L.). Plant Biotechnology Journal, 9(1), 75-87.

Asano, K., Hirai, N., Kawakita, S., Kurose, N., Nagatomo, M., Ogawa, K., Sakai, K., Takahashi, K., \& Tarumi, S. (2000). Distilled liquor product and method for producing the same. Japanese Patent No. JP2002034549A.

Bergman, C. J., Delgado, J. T., Bryant, R., Grimm, C., Cadwallader, K. R., \& Webb, 
B. D. (2000). Rapid gas chromatographic technique for quantifying 2-acetyl-1pyrroline and hexanal in rice (Oryza sativa, L.). Cereal Chemistry, 77(4), 454458.

Berner, D. K., \& Hoff, B. J. (1986). Inheritance of scent in American long grain rice. Crop Science, 26(5), 876-878.

Blank, I., Devaud, S., Fay, L. B., Cerny, C., Steiner, M., \& Zurbriggen, B. (2001). Odor-active compounds of dry-cured meat: Italian-type salami and Parma ham. In G. R. Takeoka, M. Güntert \& K.-H. Engel (Eds.), Aroma Active Compounds in Foods, (pp. 9-20). Washington, DC: American Chemical Society.

Blank, I., Devaud, S., Matthey-Doret, W., \& Robert, F. (2003). Formation of odorants in Maillard model systems based on L-proline as affected by pH. Journal of Agricultural and Food Chemistry, 51(12), 3643-3650.

Bradbury, L., Fitzgerald, T. L., Henry, R. J., Jin, Q., \& Waters, D. (2005). The gene for fragrance in rice. Plant Biotechnology Journal, 3, 363-370.

Bradbury, L., Gillies, S. A., Brusheet, D. J., Waters, D., \& Henry, R. J. (2008). Inactivation of an aminoaldehyde dehydrogenase is responsible for fragrance in rice. Plant Molecular Biology, 68(4-5), 439-449.

Bryant, R. J., \& McClung, A. M. (2011). Volatile profiles of aromatic and nonaromatic rice cultivars using SPME/GC-MS. Food Chemistry, 124, 501-513.

Buchi, G., \& Wuest, H. (1971). Synthesis of 2-acetyl-1,4,5,6-tetrahydropyridine, a constituent of bread aroma. Journal of Organic Chemistry, 36, 609-610. 
Buttery, R. G., Ling, L. C., \& Juliano, B. O. (1982). 2-Acetyl-1-pyrroline: an important aroma component of cooked rice. Chemistry and Industry, 12, 958959.

Buttery, R. G., Ling, L. C., Juliano, B. O., \& Turnbaugh, J. G. (1983). Cooked Rice Aroma and 2-Acetyl-1-Pyrroline. Journal of Agricultural and Food Chemistry, $31,823-826$.

Buttery, R. G., Ling, L. C., \& Mon, T. R. (1986). Quantitative-analysis of 2-acetyl-1pyrroline in rice. Journal of Agricultural and Food Chemistry, 34(1), 112-114.

Buttery, R. G., Turnbaugh, J. G., \& Ling, L. C. (1988). Contribution of volatiles to rice aroma. Journal of Agricultural and Food Chemistry, 36(5), 1006-1009.

Carrascon, V., Escudero, A., Ferreira, V., \& Lopez, R. (2014). Characterisation of the key odorants in a squid broth (Illex argentinus). LWT-Food Science and Technology, 57(2), 656-662.

Chi, Y., Yeung, A., \& MacLeod, A. J. (1981). A comparison of the efficiency of the Linkens and Nickerson extractor for aqueous, lipid/aqueous, and lipid samples. Journal of Agricultural and Food Chemistry, 29, 502-505.

Costello, P. J., \& Henschke, P. A. (2002). Mousy off-flavor of wine: Precursors and biosynthesis of the causative $N$-heterocycles 2-ethyltetrahydropyridine, 2acetyltetrahydropyridine, and 2-acetyl-1-pyrroline by Lactobacillus hilgardii DSM 20176. Journal of Agricultural and Food Chemistry, 50(24), 7079-7087.

Deblander, J., Van Aeken, S., Adams, A., De Kimpe, N., \& Abbaspour Tehrani, K. (2015). New short and general synthesis of three key Maillard flavour 
compounds: 2-Acetyl-1-pyrroline, 6-acetyl-1,2,3,4-tetrahydropyridine and 5acetyl-2,3-dihydro-4H-1,4-thiazine. Food Chemistry, 168, 327-331.

De Kimpe, N. G., Stevens, C. V., \& Keppens, M. A. (1993). Synthesis of 2-acetyl-1pyrroline, the principal rice flavor component. Journal of Agricultural and Food Chemistry, 41(9), 1458-1461.

De Kimpe, N. G., \& Keppens, M. A.. (1996). Novel syntheses of the major flavor components of bread and cooked rice. Journal of Agricultural and Food Chemistry, 44(6), 1515-1519.

De Zeeuw, J., Stricek, R., \& Stidsen, G. (2011). An advanced base-deactivated capillary column for analysis of volatile amines, ammonia, and alcohols. American Laboratory, 43(2), 37-40.

Du, X., \& Qian, M. (2008). Quantification of 2,5-dimethyl-4-hydroxy-3(2H)-furanone using solid-phase extraction and direct microvial insert thermal desorption gas chromatography-mass spectrometry. Journal of Chromatography A, 1208, 197-201.

Duby, P., \& Huynh-Ba, T. (1993). Process for the preparation of 2-acetyl-1-pyrroline in encapsulated form, the intermediate compound and end product obtained. Canada Patent No. CA2084256 (A1).

Duby, P., \& Huynh-Ba, T. (1996). Compositions containing 2-acetyl-1-pyrroline. United States Patent No. US5512290(A).

Engel, W., Bahr, W., \& Schieberle, P. (1999). Solvent assisted flavour evaporation - a new and versatile technique for the careful and direct isolation of aroma 
compounds from complex food matrices. European Food Research and Technology, 209, 237-241.

Erten, E. S., \& Cadwallader, K. (2017). Identification of predominant aroma components of raw, dry roasted and oil roasted almonds. Food Chemistry, 217, $244-253$.

Fang, M.-C., \& Cadwallader, K. R. (2014). Stabilization of the potent odorant 2acetyl-1-pyrroline and structural analogues by complexation with zinc halides. Journal of Agricultural and Food Chemistry, 62(35), 8808-8813.

Favino, T. F., Fronza, G., Fuganti, C., Fuganti, D., Grasselli, P., \& Mele, A. (1996). Penicillin acylase-mediated synthesis of 2-acetyl-1-pyrroline and of 2propionyl-1-pyrroline, key roast-smelling odorants in food. Inclusion complexes with beta-cyclodextrin and their NMR and MS characterization. Journal of Organic Chemistry, 61(25), 8975-8979.

Fitzgerald, T. L., Waters, D., Brools, L. O., \& Henry, R. J. (2010). Fragrance in rice (Oryza sativa) is associated with reduced yield under salt treatment. Environmental and Experimental Botany, 68(3), 292-300.

Fothergill, J. C., \& Guest, J. R. (1977). Catabolism of L-lysine by Pseudomonas aeruginosa. Journal of General Microbiology, 99(1), 139-155.

Frauendorfer, F., \& Schieberle, P. (2008). Changes in key aroma compounds of criollo cocoa beans during roasting. Journal of Agricultural and Food Chemistry, 56(21), 10244-10251.

Fuganti, C., Gatti, F. G., \& Serra, S. (2007). A general method for the synthesis of the 
most powerful naturally occurring Maillard flavours. Tetrahedron, 63(22), $4762-4767$.

Funsueb, S., Krongchai, C., Mahatheeranont, S., \& Kittiwachana, S. (2016). Prediction of 2-acetyl-1-pyrroline content in grains of Thai Jasmine rice based on planting condition, plant growth and yield component data using chemometrics. Chemometrics and Intelligent Laboratory Systems, 156, 203210.

Golam, F., Yin, Y. H., Masitah, A., Afnierna, N., Majid, N. A., Khalid, N., \& Osman, M. (2011). Analysis of aroma and yield components of aromatic rice in Malaysian tropical environment. Australian Journal of Crop Science, 5(11), $1318-1325$.

Goodwin, J., Koop, L. A., Rister, M. E., Miller, R. K., Maca, J. V., Chambers, E., Hollingsworth, M., Bett, K., Webb, B. D., \& Mcclung, A. M. (1996). Developing a common language for the U. S. rice industry: linkages among breeders, producers, processors and consumers. TAMRC Consumer Product Market Research CP2-96. Texas A\&M: College Station.

Grosshauser, S., \& Schieberle, P. (2013). Characterization of the key odorants in panfried white mushrooms (Agaricus bisporus L.) by means of molecular sensory science: comparison with the raw mushroom tissue. Journal of Agricultural and Food Chemistry, 61(16), 3804-3813.

Handoko, D. D. (2014). Ph.D. Thesis: An investigation of Flavour Formation in Cooked Rice under Boiling and High Temperature Heating Condition. 
911 Harrison, T. J., \& Dake, G. R. (2005). Expeditious, high-yielding construction of the food aroma compounds 6-acetyl-1,2,3,4-tetrahydropyridine and 2-acetyl-1pyrroline. Journal of Organic Chemistry, 70(26), 10872-10874.

He, Q., \& Park, Y. J. (2015). Discovery of a novel fragrant allele and development of functional markers for fragrance in rice. Molecular Breeding 35(11), article 217.

Herderich, M., Costello, P. J., Grbin, P. R., \& Henschke, P. A. (1995). Occurrence of 2-acetyl-1-pyrroline in mousy wines. Natural Product Letters, 7(2), 129-132.

Hinge, V. R., Patil, H. B., \& Nadaf, A. B. (2016). Aroma volatile analyses and 2AP characterization at various developmental stages in Basmati and Non-Basmati scented rice (Oryza sativa L.) cultivars. Rice, 9, 22.

Hofmann, T., \& Schieberle, P. (1998a). New and convenient syntheses of the important roasty, popcorn-like smelling food aroma compounds 2-acetyl-1pyrroline and 2-acetyltetrahydropyridine from their corresponding cyclic alpha-amino acids. Journal of Agricultural and Food Chemistry, 46(2), 616619.

Hofmann, T., \& Schieberle, P. (1998b). 2-Oxopropanal, hydroxy-2-propanone, and 1pyrroline: Important intermediates in the generation of the roast-smelling food flavor compounds 2-acetyl-1-pyrroline and 2-acetyltetrahydropyridine. Journal of Agricultural and Food Chemistry, 46(6), 2270-2277.

Hopfer, H., Jodari, F., Negre-Zakharov, F., Wylie, P. L., \& Ebeler, S. E. (2016). HS- 
SPME-GC-MS/MS Method for the Rapid and Sensitive Quantitation of 2Acetyl-1-pyrroline in Single Rice Kernels. Journal of Agricultural and Food Chemistry 64(20), 4114-4120.

Huang, T. C., Teng, C. S., Chang, J. L., Chuang, H. S., Ho, C. T., \& Wu, M. L. (2008). Biosynthetic mechanism of 2-acetyl-1-pyrroline and its relationship with 1pyrroline-5-carboxylic acid and methylglyoxal in aromatic rice (Oryza sativa L.) callus. Journal of Agricultural and Food Chemistry, 56(16), 7399-7404.

Itani, T., Tamaki, M., Hayata, Y., Fushimi, T., \& Hashizume, K. (2004). Variation of 2acetyl-1-pyrroline concentration in aromatic rice grains collected in the same region in Japan and factors affecting its concentration. Plant Production Science, 7(2), 178-183.

Jacoby, W. B., \& Fredericks, J. (1959). Pyrrolidine and putrescine metabolism: $\gamma$ aminobutyraldehyde dehydrogenase. Journal of Biological Chemistry, 234(8), $2145-2150$.

Jezussek, M., Juliano, B. O., \& Schieberle, P. (2002). Comparison of key aroma compounds in cooked brown rice varieties based on aroma extract dilution analyses. Journal of Agricultural and Food Chemistry, 50(5), 1101-1105.

Kaneko, S., Sakai, R., Kumazawa, K., Usuki, M., \& Hishimura, O. (2013). Key aroma compounds in roasted in-shell peanuts. Bioscience, Biotechnology, and Biochemistry, 77(7), 1467-1473.

Kiefl, J., Pollner, G., \& Schieberle, P. (2013). Sensomics analysis of key hazelnut odorants (Corylus avellana L. 'Tonda gentile') using comprehensive two- 
dimensional gas chromatography in combination with time-of-flight mass spectrometry (GC $\times$ GC-TOF-MS). Journal of Agricultural and Food Chemistry, 61, 5226-5235.

Kim, K. H. (1964). Purification and properties of a diamine $\alpha$-ketoglutarate transaminase from Escherichia coli. Journal of Biological Chemistry, 239, 783-786.

Kovach, M. J., Calingacion, M. N., Fitzgerald, M. A., \& McCouch, S. R. (2009). The origin and evolution of fragrance in rice (Oryza sativa L.). PNAS, 106(34), 14444-14449.

Lasekan, O., Buettner, A., \& Christlbauer, M. (2007). Investigation of important odorants of palm wine (Elaeis guineensis). Food Chemistry, 105(1), 15-23.

Likens, S. T., \& Nickerson, G. B. (1964). Determination of certain hop oil constituents in brewing products. American Society of Brewing Chemistry Proceedings, 5-13.

Limpawattana, M., \& Shewfelt, R. L. (2010). Flavor lecicon for sensoy descriptive profiling of different rice types. Journal of Food Science, 75, 199-205.

Limpawattana, M., Yang, D. S., Kays, S. J., \& Shewfelt, R. L. (2008). Relating sensory descriptors to volatile components in flavor for specialty rice types. Journal of Food Science, 73(9), 456-461.

Liu, J., Liu, M., He, C., Song, H., Guo, J., Wang, Y., Yang, H., \& Su, X. (2015). A comparative study of aroma-active compounds between dark and milk chocolate: relationship to sensory perception. Journal of the Science of Food 
Lizarraga-Guerra, R., Guth, H., \& Lopez, M. G. (1997). Identification of the most potent odorants in huitlacoche (Ustilago maydis) and austern pilzen (Pleurotus $s p$.) by aroma extract dilution analysis and static head-space samples. Journal of Agricultural and Food Chemistry, 45, 1329-1332.

Mahattanatawee, K., \& Rouseff, R. L. (2014). Comparison of aroma active and sulfur volatiles in three fragrant rice cultivars using GC-Olfactometry and GC-PFPD. Food Chemistry, 154, 1-6.

Majcher, M. A., Klensporf-Pawlik, D., Dziadas, M., \& Jeleń, H. H. (2013). Identification of aroma active compounds of cereal coffee brew and its roasted ingredients. Journal of Agricultural and Food Chemistry, 61, 2648-2654.

Maraval, I., Mestres, C., Pernin, K., Ribeyre, F., Boulanger, R., Guichard, E., \& Gunata, Z. (2008). Odor-active compounds in cooked rice cultivars from Camargue (France) analyzed by GC-O and GC-MS. Journal of Agricultural and Food Chemistry, 56(13), 5291-5298.

Maraval, I., Sen, K., Agrebi, A., Menut, C., Morere, A., Boulanger, R., Gay, F., Mestres, C., \& Gunata, Z. (2010). Quantification of 2-acetyl-1-pyrroline in rice by stable isotope dilution assay through headspace solid-phase microextraction coupled to gas chromatography-tandem mass spectrometry. Analytica Chimica Acta, 675,148-155.

Mathure, S. V., Wakte, K. V., Jawali, N., \& Nadaf, A. B. (2011). Quantification of 2acetyl-1-pyrroline and other rice aroma volatiles among Indian scented rice 
cultivars by HS-SPME/GC-FID. Food Analytical Methods, 4(3), 326-333.

Mathure, S. V., Jawali, N., Thengane, R. J., \& Nadaf, A. B. (2014). Comparative quantitative analysis of headspace volatiles and their association with BADH2 marker in non-basmati scented, basmati and non-scented rice (Oryza sativa L.) cultivars of India. Food Chemistry, 142, 383-391.

Metafa, M., \& Economou, A. (2013). Comparison of solid-phase extraction sorbents for the fractionation and determination of important free and glycosidicallybound variental aroma compounds in wines by gas chromatography-mass spectrometry. Central European Journal of Chemistry, 11(2), 228-247.

Nadaf, A. B., Krishnan, S., \& Wakte, K. V. (2006). Histochemical and biochemical analysis of major aroma compound (2-acetyl-1-pyrroline) in basmati and other scented rice (Oryza sativa L.). Current Science, 91(11), 1533-1536.

Oishi, H., \& Ebina, M. (2005). Isolation of cDNA and enzymatic properties of betaine aldehyde dehydrogenase from Zoysia tenuifolia. Journal of Plant Physiology, 162(10), 1077-1086.

Paule, C. M., \& Powers, J. J. (1989). Sensory and chemical examination of aromatic and nonaromatic rice. Journal of Food Science, 54, 1515-1520.

Peter, K. V. (2006). Handbook of Herbs and Spices (1 ed. Vol. 3). Cambridge: Woodhead Publishing Limited.

Piggott, J. R., Morrison, W. R., \& Clyne, J. (1991). Changes in lipids and in sensory attributes on storage of rice amilled to different degrees. International Journal of Food Science and Technology, 26, 615-628. 
1020

1021

1022

1023

1024

1025

1026

1027

1028

1029

1030

1031

1032

1033

1034

1035

1036

1037

1038

1039

1040

1041

Poonlaphdecha, J., Gantet, P., Maraval, I., Sauvage, F., Menut, C., Morere, A., Boulanger, R., Wust, M., \& Gunata, Z. (2016). Biosynthesis of 2-acetyl-1pyrroline in rice calli cultures: demonstration of 1-pyrroline as alimiting substrate. Food Chemistry, 197, 965-971.

Rewicki, D., Tressl, R., Ellerbeck, U., Kersten, E., Burgert, W., Gorzynski, M., Hauck, R. S., \& Helak, B. (1993). Formation and synthesis of some Maillard generated aroma compounds. In: Peter Schreier \& Peter Winterhalter (eds.) Progress in Flavor Precursor Studies (pp. 301-314). Carol Stream: Allured Publishing Corporation, .

Rhodes, D., Handa, S., \& Bressan, R. A. (1986). Metabolic changes associated with adaptation of plant cells to water stress. Plant Physiology, 82, 890-903.

Richard, T. (2001). Rice composition for coating foods. United States Patent No. US6274183 B1.

Romanczyk, L. J., McClelland, C. A., Post, L. S., \& Aitken, W. M. (1995). Formation of 2-acetyl-1-pyrroline by several Bacillus cereus strains isolated from cocoa fermentation boxes. Journal of Agricultural and Food Chemistry, 43(2), 469475.

Ruckriemen, J., Schwarzenbolz, U., Adam, S., \& Henle, T. (2015). Identification and quantitation of 2-acetyl-1-pyrroline in Manuka honey (Leptospermum scoparium). Journal of Agricultural and Food Chemistry, 63, 8488-8492.

Sakthivel, K., Sundaram, R. M., Rani, N. S., Balachandran, S. M., \& Neeraja, C. N. (2009). Genetic and molecular basis of fragrance in rice. Biotechnology 
1043

1044

1045

1046

1047

1048

1049

1050

1051

1052

1053

1054

1055

1056

1057

1058

1059

1060

1061

1062

1063

Schieberle, P. (1988). Effects of additions of proline on formation of the aroma compound 2-acetyl-1-pyrroline in white bread crust. Getreide, Mehl und Brot, 42(11), 334-335.

Schieberle, P. (1989). Formation of 2-acetyl-1-pyrroline and other important flavor compounds in wheat bread crust. In T. H. Parliment, R. J. McGorrin \& C. T. Ho (Eds.), Thermal Generation of Aromas (pp. 268-275). Washington, D.C.: American Chemical Society.

Schieberle, P. (1990). The role of free amino-acids present in yeast as precursors of the odorants 2-acetyl-1-pyrroline and 2-acetyltetrahydropyridine in wheat bread crust. Zeitschrift für Lebensmittel-Untersuchung und -Forschung, 191(3), 206-209.

Schieberle, P. (1991). Primary odorants in popcorn. Journal of Agricultural and Food Chemistry, 39(6), 1141-1144.

Schieberle, P. (1995). Quantitation of important roast-smelling odorants in popcorn by stable-isotope dilution assays and model studies on flavor formation during popping. Journal of Agricultural and Food Chemistry, 43(9), 2442-2448.

Schieberle, P., \& Grosch, W. (1987). Quantitative-analysis of aroma compounds in wheat and rye bread crusts using a stable isotope-dilution assay. Journal of Agricultural and Food Chemistry, 35(2), 252-257.

Seitz, L. M., Wright, R. L., Waniska, R. D., \& Rooney, L. W. (1993). Contribution of 2-acetyl-1-pyrroline to odors from wetted ground pearl-millet. Journal of 
1065

1066

1067

1068

1069

1070

1071

1072

1073

1074

1075

1076

1077

1078

1079

1080

1081

1082

1083

1084

1085

Siddiq, E. A., Vemireddy, L. R., \& Nagaraju, J. (2012). Basmati rices: genetics, breeding and trade. Agricultural Research, 1(1), 25-36.

Singh, R. K., Singh, U. S., \& Khush, G. S. (2000). Aromatic Rices. New Delhi: Oxford \& IBH Publishing.

Slayton, T., \& Muniroth, S. (2015). Rice sector review: a more detailed road map for Cambodian rice exports. World Bank Working Paper, 98834.

Smith, R. L., Cohen, S. M., Doull, J., Feron, V. J., Goodman, J. I., Marnett, L. J., Portoghese, P. S., Waddell, W. J., \& Wanger, B. M. (2005). GRAS Flavouring Substances 22. Food Technology 27, 24-62.

Sood, B. C., \& Siddiq, E. A. (1978). A rapid technique for scent determination in rice. Indian Journal of Genetics and Plant Breeding, 38(2), 268-275.

Srinivas, P., Sulochanamma, G., Raghavan, B., \& Gurudutt, K. N. (2006). Process for the stabilization of 2-acetyl-1-pyrroline, the basmati rice flavorant. United States Patent No. US 20060147596 A1.

Stahnke, L. H. (2000). 2-acetyl-1-pyrroline - Key aroma compound in Mediterranean dried sausages. In P. Schieberle \& K. H. Engel (Eds.), Frontiers of Flavour Science (pp. 361-365). Garching, Germany: Deutsche Forschungsanstalt für Lebensmittelchemie.

Strauss, C. R., \& Heresztyn, T. (1984). 2-Acetyltetrahydropyridines - a cause of the mousy taint in wine. Chemistry \& Industry, 3, 109-110.

Struve, C., \& Christophersen, C. (2003). Structural equilibrium and ring-chain 

60(8), 1907-1914.

Szabados, L., \& Savouré, A. (2010). Proline: a multifunctional amino acid. Trends in Plant Science, 15(2), 89-97.

Tanchotikul, U., \& Hsieh, T. C. Y. (1991). An improved method for quantification of

Tava, A., \& Bocchi, S. (1999). Aroma of cooked rice (Oryza sativa): Comparison between commercial Basmati and Italina Line B5-3. Cereal Chemistry, 76(4), 526-529.

Trossat, C., Rathinasabapathi, B., \& Hanson, A. D. (1997). Transgenically expressed betaine aldehyde dehydrogenasw efficiently catalyzes oxidation of dimethylsulfoniopropionaldehyde and [omega]-aminoaldehydes. Plant Physiology, 113(4), 1457-1461.

Wagber, J., Granvogl, M., \& Schieberle, P. (2016). Characterization of the key aroma compounds in raw licorice (Glycyrrhiza glabra L.) by means of molecular sensory science. Journal of Agricultural and Food Chemistry, 64(44), 83888396.

Wakte, K., Zanan, R., Hinge, V., Khandagale, K., Nadaf, A., \& Henry, R. (2017). Thirty-three years of 2-acetyl-1-pyrroline, a principal basmati aroma compound in scented rice (Oryza sativa L.): a status review. Journal of the 
Widjaja, R., Craske, J. D., \& Wootton, M. (1996a). Changes in volatile components of paddy, brown and white fragrant rice during storage. Journal of the Science of Food and Agriculture, 71, 218-224.

Widjaja, R., Craske, J., \& Wootton, M. (1996b). Comparative studies on volatile components of non-fragrant and fragrant rices. Journal of the Science of Food and Agriculture, 70, 151-161.

Wongpornchai, S., Dumri, K., Jongkaewwattana, S., \& Sirri, B. (2004). Effects of drying methods and storage time on the aroma and milling quality of rice (Oryza sativa L.) cv. Khao Dawk Mali 105. Food Chemistry, 87(3), 407-414.

Wongpornchai, S., Sriseadka, T., \& Choonvisase, S. (2003). Identification and quantitation of the rice aroma compound, 2-acetyl-1-pyrroline, in bread flowers (Vallaris glabra ktze). Journal of Agricultural and Food Chemistry, $51(2), 457-462$.

Yahya, F., Lu, T., Santos, R. C. D., Fryer, P. J., \& Bakalis, S. (2010). Supercritical carbon dioxide and solvent extraction of 2-acetyl-1-pyrroline from pandan leaf: The effect of pre-treatment. Journal of Supercritical Fluids, 55(1), 200207.

Yang, D. S., Shewfelt, R. L., Lee, K. S., \& Kays, S. J. (2008). Comparison of odoractive compounds from six distinctly different rice flavor types. Journal of Agricultural and Food Chemistry, 56(8), 2780-2787.

Yau, N. J. N., \& Liu, T. T. (1999). Instrumental and sensory analysis of volatile aroma 
1131

Yoshihashi, T. (2002). Quantitative analysis on 2-acetyl-1-pyrroline of an aromatic rice by stable isotope dilution method and model studies on its formation during cooking. Journal of Food Science, 67(2), 619-622.

Yoshihashi, T., Huong, N. T. T., \& Inatomi, H. (2002). Precursors of 2-acetyl-1pyrroline, a potent flavor compound of an aromatic rice variety. Journal of Agricultural and Food Chemistry, 50(7), 2001-2004.

Yoshihashi, T., Nguyen, T. T. H., \& Kabaki, N. (2004). Area dependency of 2-acetyl1-pyrroline content in an aromatic rice variety, Khao Dawk Mali 105. Japan Agricultural Research Quarterly, 38(2), 105-109.

Zanan, R., Khandagale, K., Hinge, V., Elangovan, M., Henry, R. J., \& Nadaf, A. (2016). Characterization of fragrance in sorghum (Sorghum bicolor (L.) Moench) grain and development of a gene-based marker for selection in breeding. Molecular Breeding, 36(11), 12. 
1146

1147

1148

1149

1150

1151

1152

1153

1154

1155

1156

1157

1158

1159

1160

1161

1162

1163

1164

Figure 1. A comparison of the (a) BADH2-dependent 2AP biosynthetic pathway (Bradbury, Gillies, Brusheet, Waters, \& Henry, 2008) and the (b) BADH2independent 2AP biosynthetic pathway (Sakthivel et al., 2009; Huang et al., 2008).

Figure 2. Mechanism of 2-AP formation through the heterolactic pathway (Costello \& Henschke, 2002)

Figure 3. 2-AP Maillard Reaction formation pathways: a) formation of 1-pyrroline from ornithine (Schieberle, 1990); b) formation of 1-pyrroline from proline and 1-deoxyosone (Schieberle, 1995); c) 13C-labelled and unlabelled 2-AP formation from 1-pyrroline and 13C-glucose (Rewicki et al., 1993).

Figure 4. 2-AP synthesis strategies: a) Buttery, Ling, Juliano, and Turnbaugh, 1983; b) De Kimpe, Stevens, and Keppens, 1993; c. De Kimpe, Stevens, and Keppens, 1993; d) De Kimpe, and Keppens, 1996; e) Favino, Fronza, Fuganti, Fuganti, Grasselli, and Mele, 1996; f) Deblander, Van Aeken, Adams, De Kimpe, \& Abbaspour Tehrani (2015).

LDA: lithium diisopropylamide; THF: tetrahydrofuran; PGA: immobilised penicillin G acylase; DMT: dimethyltitanocene; TFA: trifluoroacetic acid 
(a) BADH2-dependent 2-AP synthesls

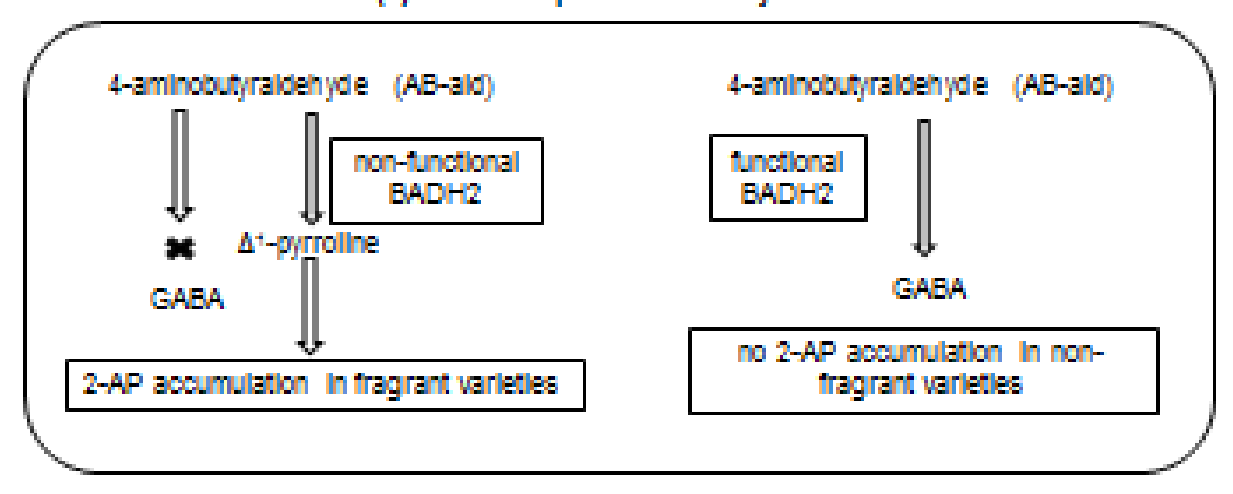

(b) BADH2-Independent 2-A.P synthesls

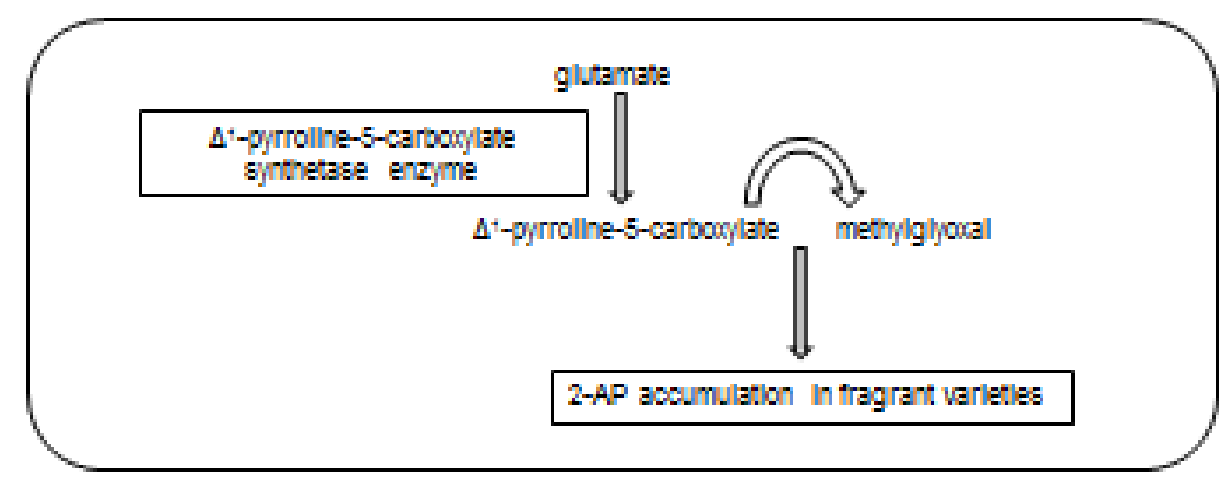

Figure 1 


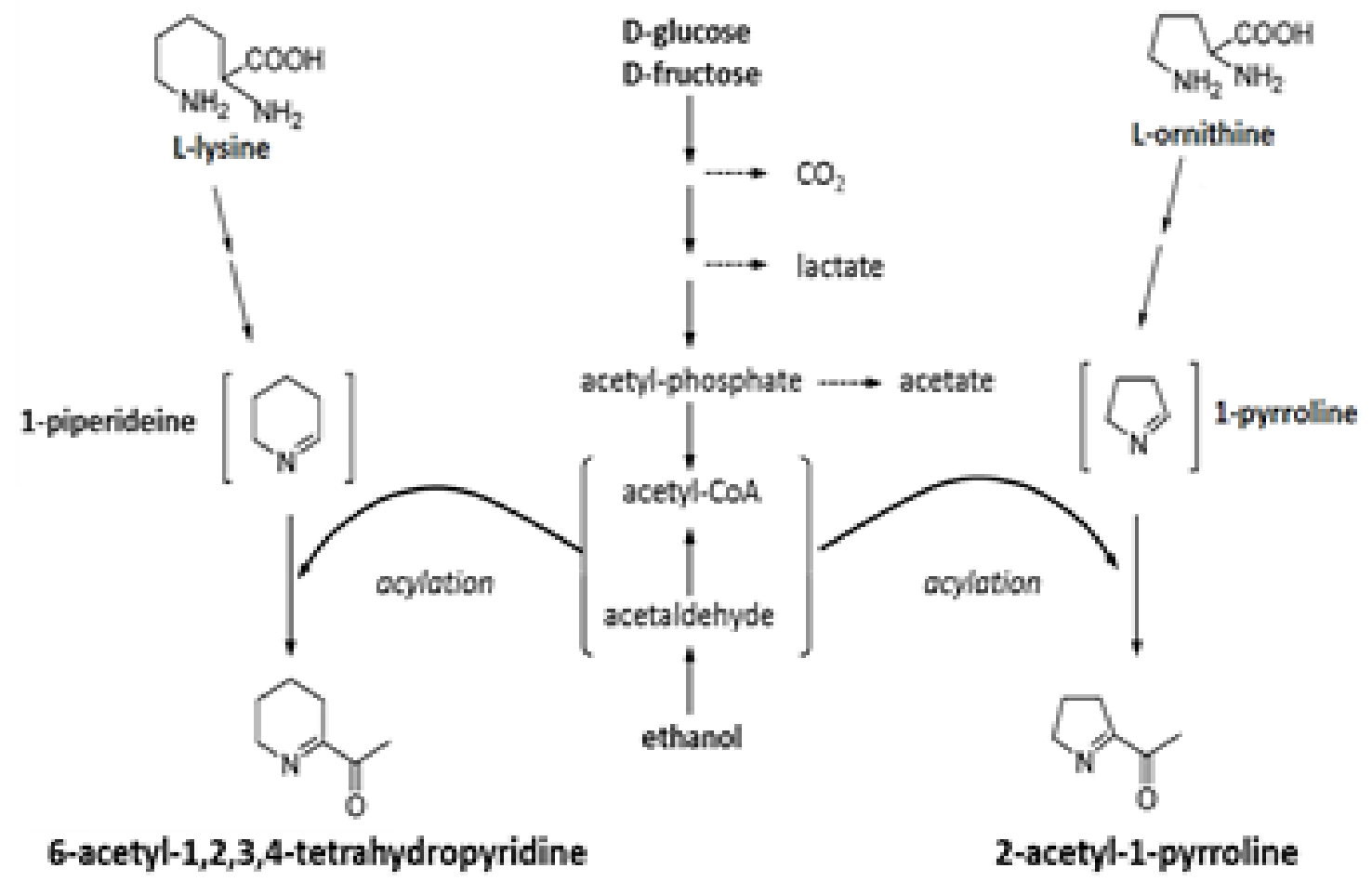

Figure 2 
a)

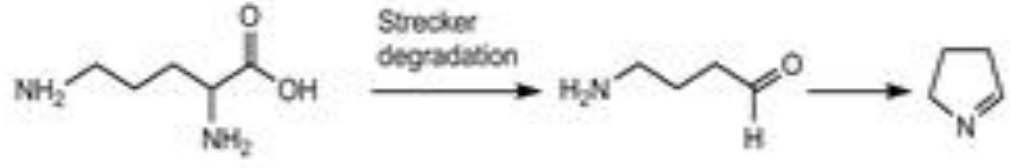

b)<smiles>C=C=CC(=O)C(=CC(O)CO)C(=CC(=O)O)N1CCCC1</smiles><smiles>C=C=CC(=O)C(=CC(C)=O)N1C=CCC1</smiles>

c)
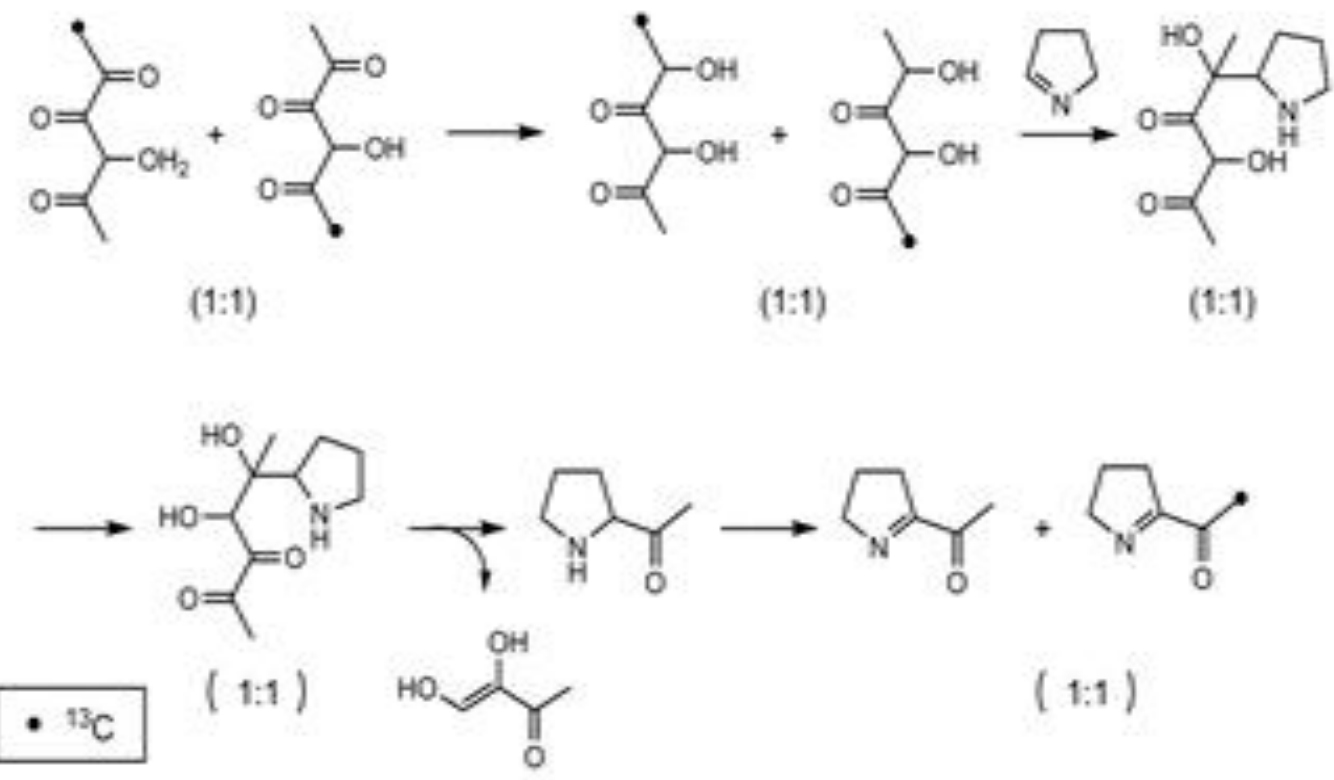

Figure 3 
a)

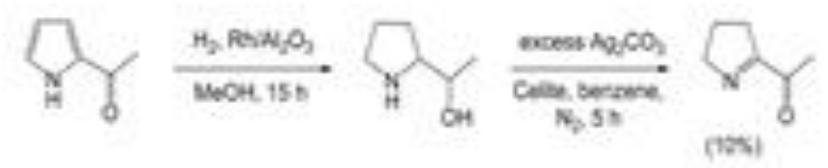

b)

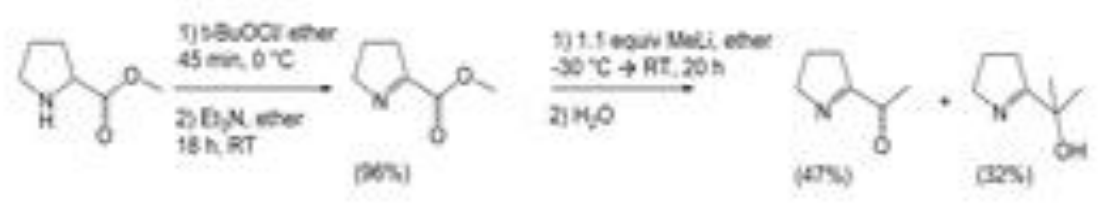

c)

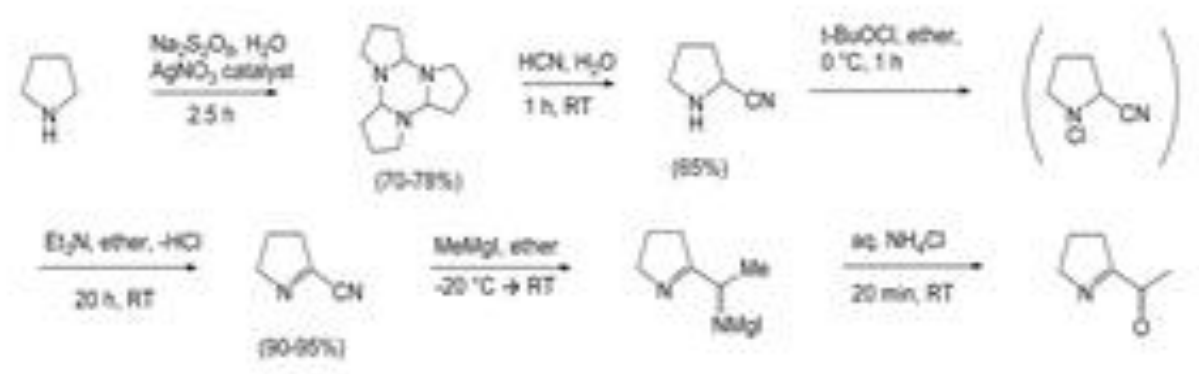

d)

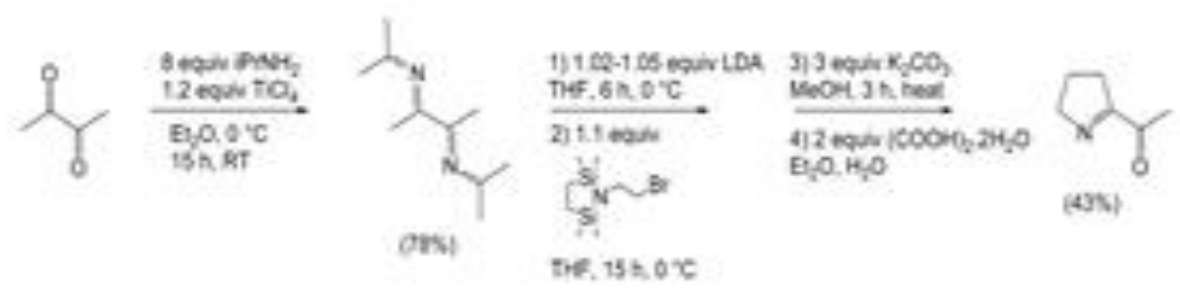

e)

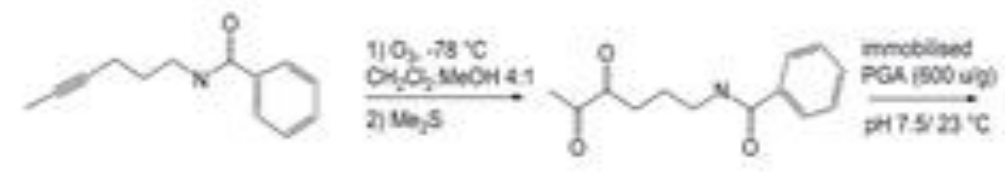<smiles>CC(O)C1CCCN1</smiles>

f)

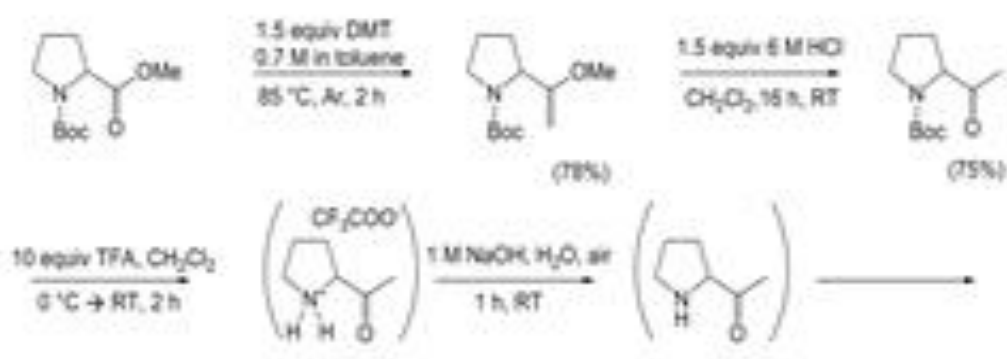

\section{Figure 4}


Table 1: 2-AP concentrations in fragrant and non-fragrant rice

\begin{tabular}{|c|c|c|}
\hline \multirow[t]{2}{*}{ rice variety } & \multicolumn{2}{|c|}{$\begin{array}{l}\text { 2-AP concentration } \\
\qquad(\mu \mathrm{g} / \mathrm{kg})\end{array}$} \\
\hline & milled & brown \\
\hline \multicolumn{3}{|l|}{ fragrant rice } \\
\hline \multirow[t]{5}{*}{ Basmati } & $60^{\mathrm{a}}$ & $170^{\mathrm{a}}$ \\
\hline & $87^{\mathrm{d}}$ & $610^{\mathrm{b}}$ \\
\hline & $588^{\mathrm{g}}$ & $119^{\mathrm{h}}$ \\
\hline & $19-342^{\mathrm{h}}$ & \\
\hline & $434^{\mathrm{k}}$ & \\
\hline \multirow[t]{2}{*}{ Khao Dawk Mali 105} & $70^{\mathrm{a}}$ & $200^{\mathrm{a}}$ \\
\hline & $87-532^{i}$ & \\
\hline \multirow{2}{*}{ Malagkit Sungsong } & $90^{\mathrm{a}}$ & $200^{\mathrm{a}}$ \\
\hline & & $760^{\mathrm{b}}$ \\
\hline Milagross & $70^{\mathrm{a}}$ & \\
\hline Seratus Malam & $60^{\mathrm{a}}$ & \\
\hline Azucena & $40^{\mathrm{a}}$ & $160^{\mathrm{a}}$ \\
\hline Hieri & $40^{\mathrm{a}}$ & $100^{\mathrm{a}}$ \\
\hline \multirow[t]{2}{*}{ Ir841-76-1 } & $70^{\mathrm{a}}$ & $200^{\mathrm{a}}$ \\
\hline & & $560^{\mathrm{b}}$ \\
\hline \multirow[t]{2}{*}{ Jasmine } & $156^{\mathrm{d}}$ & $550^{\mathrm{h}}$ \\
\hline & $810^{\mathrm{h}}$ & \\
\hline Della & $76^{\mathrm{d}}$ & \\
\hline Goolarah & $691^{\mathrm{e}}$ & \\
\hline Yrf9 & $670^{\mathrm{e}}$ & $344^{\mathrm{f}}$ \\
\hline B5-3 & $2746^{\mathrm{g}}$ & \\
\hline \multicolumn{2}{|l|}{ Amber Aromatic (Lundberg) } & $345^{\mathrm{h}}$ \\
\hline Aromatic (Fowler Gourmet) & $999^{\mathrm{h}}$ & \\
\hline \multicolumn{2}{|l|}{ Black Thai (Bulk) } & $259^{\mathrm{h}}$ \\
\hline Jasmati (Rice Tec) & $526^{\mathrm{h}}$ & \\
\hline Kasmati (Rice Tec) & $496^{\mathrm{h}}$ & \\
\hline Texmati (Rice Tec) & $266^{\mathrm{h}}$ & \\
\hline Aychade & $575-638^{j}$ & \\
\hline Fidji & $45-475^{j}$ & \\
\hline Giano & $28-336^{j}$ & \\
\hline Kala Bhat & $920^{\mathrm{k}}$ & \\
\hline Kali Kumud & $732^{\mathrm{k}}$ & \\
\hline Amritbhog & $787^{\mathrm{k}}$ & \\
\hline \multicolumn{3}{|l|}{ non-fragrant rice } \\
\hline Calrose & $<6^{\mathrm{a}}$ & \\
\hline California Long-Grain & $0.6^{\mathrm{c}}$ & \\
\hline \multirow[t]{2}{*}{ Pelde } & $15^{\mathrm{e}}$ & \\
\hline & & \\
\hline
\end{tabular}




$\begin{array}{lc}\text { Texas Long Grain } & <8^{\mathrm{a}} \\ & 6^{\mathrm{b}} \\ \text { Ariette } & 10.6^{\mathrm{j}} \\ \text { Ruille } & 24.7^{\mathrm{j}} \\ \text { Sonsali } & 72^{\mathrm{k}} \\ \text { Kolamb } & 125^{\mathrm{k}}\end{array}$

Data are from the following references: a Buttery et al., 1983; 'buttery et al., 1986;

1177 ' Buttery et al., 1988; ${ }^{\mathrm{d}}$ Tanchotikul and Hsieh, 1991; ${ }^{\mathrm{e}}$ Widjaja et al., 1996a; ${ }^{\mathrm{f}}$ Widjaja et 1178 al., 1996b; ' $\mathrm{T}$ Tava and Bocchi, 1999; ' Bergman et al., 2000; 'Yoshihashi et al., 2004; 1179 jMaraval et al., 2010; ${ }^{\mathrm{j}}$ Mathure et al., 2014. 
Table 2: 2-AP concentrations in foods other than rice

\begin{tabular}{lc}
\hline \multicolumn{1}{c}{ food sample } & $\begin{array}{c}\text { 2-AP concentration } \\
(\mu \mathrm{g} / \mathrm{kg})\end{array}$ \\
\hline wheat bread crusts & $75^{\mathrm{a}}$ \\
Mediterranean dried sausages & $750^{\mathrm{b}}$ \\
bread flowers (Vallaris glabra ktze) & $3.36(\mathrm{fresh})$ \\
& $26.1(\mathrm{dry})^{\mathrm{c}}$ \\
palm wine & $11.4^{\mathrm{d}}$ \\
roasted Criollo cocoa beans & $4.2^{\mathrm{e}}$ \\
pandan leaves & $40-450^{\mathrm{f}}$ \\
pan-fried mushrooms & $4.2-7.0^{\mathrm{g}}$ \\
roasted in-shell peanuts & $1920^{\mathrm{h}}$ \\
roasted hazelnuts & $85^{\mathrm{i}}$ \\
cereal coffee brew & $8^{\mathrm{j}}$ \\
squid broth & $97.3^{\mathrm{k}}$ \\
dark chocolate & $21^{1}$ \\
milk chocolate & $3^{1}$ \\
cocoa liquor & $11^{1}$ \\
Manuka honey & $80-450^{\mathrm{m}}$ \\
raw licorice & $9.41^{\mathrm{n}}$ \\
roasted almonds & $12(\mathrm{dry} \mathrm{roasted})^{\mathrm{O}}$ \\
& $30(\mathrm{oil} \mathrm{roasted})^{\mathrm{O}}$ \\
\hline
\end{tabular}

Data are from the following references: ${ }^{a}$ Schieberle and Grosch, 1987; ${ }^{b}$ Stahnke, 2000; ' Wongpornchai et al., 2003; ${ }^{\mathrm{d}}$ Lasekan et al., 2007; ${ }^{\mathrm{e}}$ Frauendorfer and Schieberle, 2008; ' Yahya et al., 2010; ' Grosshauser \& Schieberle, 2013; ' $K a n e k o$ et al., 2013; 'Kiefl et al., 2013; ${ }^{\mathrm{j}}$ Majcher et al., 2013; ${ }^{\mathrm{k}}$ Carrascon et al., 2014; ' Liu et al., 2015; ${ }^{\mathrm{m}}$ Ruckriemen et al., 2015; ${ }^{\mathrm{n}}$ Wagber et al., 2016; ${ }^{\circ}$ Erten et al., 2017. 